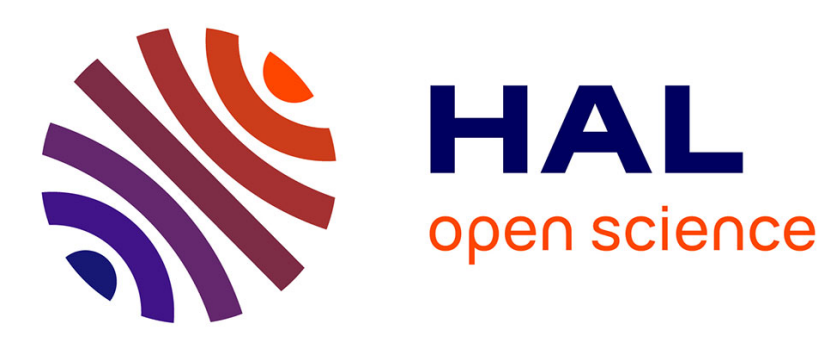

\title{
Epidemiological transition and the wealth of nations: the case of HIV/AIDS in a microsimulation model
}

\author{
Yves Arrighi, Bruno Ventelou
}

\section{To cite this version:}

Yves Arrighi, Bruno Ventelou. Epidemiological transition and the wealth of nations: the case of HIV/AIDS in a microsimulation model. Revue d'Economie Politique, 2019, 129 (4), pp.591-618. 10.3917/redp.294.0591 . hal-02475615

\section{HAL Id: hal-02475615 https://hal-amu.archives-ouvertes.fr/hal-02475615}

Submitted on 12 Feb 2020

HAL is a multi-disciplinary open access archive for the deposit and dissemination of scientific research documents, whether they are published or not. The documents may come from teaching and research institutions in France or abroad, or from public or private research centers.
L'archive ouverte pluridisciplinaire HAL, est destinée au dépôt et à la diffusion de documents scientifiques de niveau recherche, publiés ou non, émanant des établissements d'enseignement et de recherche français ou étrangers, des laboratoires publics ou privés. 


\section{Epidemiological transition and the wealth of nations: the case of HIV/AIDS in a microsimulation model}

Version du 21 Septembre 2018 (dernière édition : 28/02/2019 - mise en forme)

\section{Auteurs :}

Auteur correspondant : Yves Arrighi (Maître de Conférences) : Lille Economie et Management (LEM, UMR 9221) - Université de Lille. Adresse : Maison de la Recherche, Domaine universitaire du pont de bois; 59653 Villeneuve d'Ascq. Téléphone: 0320416489 . Courriel : yves.arrighi@univ-lille.fr

Bruno Ventelou (Directeur de recherche CNRS) : Aix-Marseille Université, CNRS, EHESS, Centrale Marseille, Aix-Marseille School of Economics. Adresse : AMSE, 5-9 Bd Bourdet ; 13205 Marseille Cedex 1. Téléphone : 04135525 82. Courriel : bruno.ventelou@univ-amu.fr 
Titre en français : "Transition épidémiologique et richesse des nations : micro-simulations dans le cas du VIH/SIDA»

Résumé (200 mots) : Cet article vise à décomposer l'effet de programmes curatifs sur la performance macroéconomique de pays en développement en phase de transition épidémiologique. Il est largement admis dans la littérature que les programmes d'accès aux soins génèrent des gains de productivité chez les travailleurs en mauvaise santé. Cependant, ces programmes modifient par nature la taille et la composition de la population active en augmentant la proportion d'individus souffrant de maladies chroniques, atténuant ainsi l'effet sur la productivité moyenne. Après avoir défini les conditions théoriques nécessaires à ce que cet effet de structure supplante l'effet productif de l'accès aux soins, nous transposons cette investigation au cas des programmes de traitements antirétroviraux dans trois pays d'Afrique subsaharienne touchés par le VIH/SIDA. Un modèle de microsimulation est utilisé pour générer ex-ante les trajectoires de santé et de production d'individus représentatifs, selon qu'ils aient ou non accès aux antirétroviraux. Nous utilisons le modèle pour générer un "contrefactuel» (en l'absence de l'effet de composition) et constatons que l'effet productif l'emporte sur l'effet épidémiologique négatif. Bien entendu, cette approche n'est qu'un indicateur des performances économiques et, en tout état de cause, ne doit pas constituer un critère de décision sur la nécessité éthique de l'accès aux soins.

Mots-clés: Changements démographiques, programmes de traitement, indicateurs macroéconomiques, microsimulation, VIH-SIDA

Abstract (202 words): This paper aims at quantifying the effect of healthcare programs on economic outcomes in the context of developing countries experiencing epidemiological transitions. It is widely accepted in the literature that treatment programs result in production gains among ill-health workers. However, these programs have the additional effect of modifying both the size and the composition of the working population by increasing the proportion of chronically-ill individuals. First, we define the theoretical conditions under which this macroepidemiological phenomenon outweighs the positive effect of an increase in production. Second, we decompose the economic consequences of access to antiretroviral treatments against HIV in three sub-Saharan African countries. Forecasts of an individual's health status, depending on whether he or she has access to medication, are generated using a microsimulation model. We use the model to generate a counterfactual (as if the adverse epidemiological effect did not exist), which allows decomposing the total impact of the HIV-medicines program into two different effects: positive and negative. We find that the positive effect of treatment procurement outweighs the negative epidemiological effect. Of course, this approach is only an indicator of economic performance and should in no way constitute a decision-making criterion about the ethical necessity of access to health care.

Keywords: Demographic changes, treatment programs, macroeconomic indicators, microsimulation, HIV/AIDS

JEL Codes: I15, J11, J21 


\section{INTRODUCTION}

A revival of the literature about the relationship between health and development took place in the recent years. The seminal book of Fogel [1993) was notably followed by Bell et al. [2003), Bloom et al. [2004), Smith et al. [2005) and the report directed by Sachs for the World Health Organization [2001]. One of the major problems is the difficulty in deciding between the two interpretations of a causality which could be bi-directional. The evidence for the "development to health" relationship could effectively cancel out another more subtle yet very real relationship: that of « health to development » Acemoglu \& Johnson [2007]; Bloom \& Canning [2000]; Weil, [2007, 2010]; Schultz [2010].

The other problem is that while (good) health has been proven to be a major motor for development, the question of public intervention remains. In fact, comprehensive relationships between healthcare programs -the level of the policy decision-, populations' health and development have rarely been demonstrated. Yet, from a public policy decision-making perspective (allocating resources as efficiently as possible to produce development), it is the whole relationship which must be demonstrated and not simply the end of the causality chain (Acemoglu \& Johnson [2007]).

For example, one could assume that treatment programs target ill-health individuals (as well as the destitute, the elderly and the unemployed), who are probably less productive, or at least less involved in activities with high productive value. In the long term, health expenditures may change the distribution of the population between those who are chronically ill (or disabled) and those who are not - since medications have the precise goal to increase the survival of those who are ill - and may therefore modify upwards their weight in the population. If one also assumes that without access to treatment the survival rate of ill-individuals is merely null, curative health expenditures may not lead to an increase in macroeconomic outcomes based on average utilitarianism (e.g. per capita GDP, poverty rate...). In this case, policy makers could thus be tempted to deny care to their less productive populations in order to-spuriously-achieve better 
economic performance; the premature death of ill individuals acting as a Malthusian "positive population shock"1.

The negative correlation between individuals' mortality and performances on the labor market suggests that social evaluation should be pay important attention to the changes in the population's size and epidemiological structure induced by public policies, and especially health programs. This raises the central question of how to assess the effect of public policies on development and social welfare while taking into account the selection process at works in our economies: with the traditional tools used to evaluate social welfare, the wellbeing of dead people is missing... Several recent works in welfare economics and health economics have however proposed to amend welfare indicators by valuing the (virtual) existence of "missing" individuals. To address the "mortality paradox" faced by standard poverty measures (the higher the mortality of the poor is, the lower is the measured poverty), Kanbur and Mukherjee [2007] and more recently Lefebvre, Pestieau and Ponthière [2013, 2017] proposed an ex-post correction of poverty measures by extending the lifetime of the prematurely dead by means of a fictitious income. In a previous work (Arrighi, Abu Zaineh and Ventelou [2015]), we adopted an ex-ante framework to assess under which conditions the rankings of health-policies based on welfare in health as well as on health inequality metrics can be altered by the inclusion of counterfactual deaths.

This paper proposes an extension of our previous research and examines the relationship between health, health programs and economic outcomes, while taking into account, in an endogenous manner, not only individuals' health -healthcare improves individuals' health condition and therefore their economic production-but also the epidemiological situation of the population (healthcare prolongs the lives of those who are ill, and transforms the disease into

\footnotetext{
${ }^{1}$ To the contrary, a preventive care program will probably not show the same kind of consequences. It must also be noted that such a quantity/quality trade-off is only at stake when a curative program targets a lethal condition and transforms it into a chronic condition. If a health condition solely leads to disabilities without consequences on survival, treatment programs do not change the composition of the population and could only increase per capita welfare.
} 
one that is "chronic"). This latter point is particularly crucial since, thanks to modern medicine, developing countries are experiencing an epidemiological transition (i.e. diseases are becoming chronic), similar to which high-income countries experienced in the $20^{\text {th }}$ century. Unlike the previously cited works, this study does not attempt to amend economic indicators by the inclusion of some neutral welfare refinements; it rather emphasizes under which conditions a "mortality paradox" could generate a spurious decrease in the established indicator.

One field where these questions are acutely important is that of programs to fight against HIV/AIDS (Human Immunodeficiency Virus / Acquired Immune Deficiency Syndrome), which remained in 2016 the second cause of death in Africa (WHO, 2018). While AIDS considerably reduces workers' productivity and survival, antiretroviral drugs (ARVs) offer the possibility to survive from the disease and contribute towards the recovery of a certain level of productivity among people living with HIV (PLWHIV) and/but increasing the prevalence of the epidemic. The question of the economic benefit of treatment procurement programs is one condition of their sustainability in African countries.

The rest of the paper is organized as follows. First, we design a theoretical model and study the conditions under which the "epidemiological" adverse effect of treatment programs outweighs their productive effects. Second, we evaluate the magnitude of this adverse epidemiological effect in the context of ARVs procurement programs by micro-simulating the life histories of individuals drawn from Demographic \& Health Surveys of three sub-Saharan African countries, differing in terms of epidemiological and labor market situations. 


\section{THeOREtical FramewOrk}

\section{General statement}

To formalize our investigation, let us first assume a simple production function $\varphi(\cdot)$ linking per capita production $y$ and one composite production factor ${ }^{2}$, the health conditions $h_{i}$ of the population's members $i=\{1, \ldots N\}: y=\varphi\left(h_{1}, \ldots, h_{N}\right)$. We suppose that $h_{i}$ can take any value between zero and one, and that $\varphi(\cdot)$ is strictly increasing and quasi-concave in its arguments. Let us assume that there is perfect substitutability between working time of each worker and that all workers are characterized by the same individual production function $f(\cdot)$, with $f^{\prime}(\cdot)>0$ and $f^{\prime \prime}(\cdot)<0$, so that $\varphi\left(h_{1}, \ldots, h_{N}\right)=\left(f\left(h_{1}\right)+\cdots+f\left(h_{N}\right)\right) / N$, and let us consider that the population can be divided into two homogenous populations, entitled $s$ (sick) and $n s$ (not sick), enjoying two different health states $h^{s}$ and $h^{n s}>h^{s}$. The technologies can therefore be summarized by the two health conditions, and their weights $(m$, the prevalence of the disease, and $(1-m))$ in the economy:

$$
y=\varphi\left(h_{1}, \ldots, h_{N}\right)=m \cdot f\left(h^{s}\right)+(1-m) \cdot f\left(h^{n s}\right)
$$

Let us assume that the social planner can implement a health policy to limit the burden of the disease. The amount of per capita health expenditures (denoted $x$ ) influences simultaneously $h^{s}$, $m$ and (possibly) $h^{n s}$. The change in per capita production $y$ following an investment in health $x$ can be calculated by the following differential:

$$
\mathrm{d} y=\left\{\frac{\partial m}{\partial x} \cdot f\left(h^{s}\right)+m \cdot \frac{\partial h^{s}}{\partial x} \cdot \frac{\partial f\left(h^{s}\right)}{\partial h^{s}}-\frac{\partial m}{\partial x} \cdot f\left(h^{n s}\right)+(1-m) \cdot \frac{\partial h^{n s}}{\partial x} \cdot \frac{\partial f\left(h^{n s}\right)}{\partial h^{n s}}\right\} \mathrm{d} x
$$

Reorganizing [2], we obtain:

$$
\frac{\mathrm{d} y}{\mathrm{~d} x}=\underbrace{m \cdot \frac{\partial h^{s}}{\partial x} \cdot \frac{\partial f\left(h^{s}\right)}{\partial h^{s}}}_{(A)}+\underbrace{(1-m) \cdot \frac{\partial h^{n s}}{\partial x} \cdot \frac{\partial f\left(h^{n s}\right)}{\partial h^{n s}}}+\underbrace{\left(f\left(h^{s}\right)-f\left(h^{n s}\right)\right) \cdot\left(\frac{\partial m}{\partial x}\right)}
$$

$(A)$

$(B)$

\footnotetext{
${ }^{2}$ The other production factors (physical capital, education ...) are exogenous.
} 
Three components appear in equation [3] : $(A)$ captures the productive effects among the illpopulation obtained through the improvement of health care for the ill, $(B)$ represents the symmetric effect among those not ill, while $(C)$ is the product between $\left(f\left(h^{s}\right)-f\left(h^{n s}\right)\right)$, that is to say the production gap between the ill and non-ill populations before the increase of health expenditures, and the "epidemiological effect" of healthcare expenditures $\left(\frac{\partial m}{\partial x}\right)$, that is to say the fact that health spending changes the distribution between the ill and non-ill populations.

Equation [3] enables discussing the different effects seen in the introductive section. $(A)$ shows that healthcare expenditures can translate into improvements in the health condition of ill-health individuals $\left(\frac{\partial h^{s}}{\partial x} \geq 0\right)$ and, in turn, that these health enhancements may increase production $\left(\frac{\partial f\left(h^{s}\right)}{\partial h^{s}} \geq 0\right)$. The relationship between health programs, health, and development is usually described by this direct channel. Health programs may also increase the economic production of healthy individuals (component $(B)$ ): on the one hand, providing care to the ill-health population may create a positive production synergy with healthy individuals (however this is not taken into account by equation [3]); on the other hand, if the health expenditures consist in vaccination or preventive medicine, the health condition and therefore the productivity of initially healthyindividuals could also rise as they are less likely to contract the disease.

Regarding the composition of the last component $(C)$, we assume that the productive capacity of the ill is lower than that of non-ill populations $\left(\left(f\left(h^{s}\right)-f\left(h^{n s}\right)\right)<0\right)$. Therefore, $(C)$ could impact positively or negatively the effect of health expenditures on production whether $\frac{\partial m}{\partial x}$ is positive or negative. Concerning this latter effect, it is generally difficult to sign at first sight the epidemiological effect $\frac{\partial m}{\partial x}$. In some cases, health expenditures can contribute in reducing $m$ (for example when the health program consists in vaccination and /or primary prevention). In this case, $(C)$ reinforces the positive effects $(A)$ and $(B)$. Nevertheless, the main part of the health effort is usually curative, i.e.: directed towards improving the survival of ill-health individuals. This leads to modify, upwards, the population of ill people in the economy (diseases becoming chronic): $\frac{\partial m}{\partial x}>0$. In this case, the third term of equation [3] is negative, which in turn weakens 
the total productive yield of healthcare expenditure $\left(\frac{\mathrm{d} y}{\mathrm{~d} x}\right)$. The importance of the epidemiological effect $(C)$ in equation [3] relative to the other components $(A)$ and $(B)$ requires further discussion.

\section{Two-Period Model}

We design a two-period model to illustrate more precisely the epidemiological effect of treatment programs induced by mortality changes. In period 1, a resource-constrained country hit by an epidemic receives foreign aid that is immediately spent on medicines to limit the burden of the disease (we assume that this aid not used for other purposes, such as prevention campaigns). This aid flow has immediate consequences on health and economic outcomes, but lets the first period's population structure unchanged. The second period integrates the demographic changes induced by the policy.

We capture the effect of the policy on individuals' health condition by $\Delta=\delta(x)$, with $\delta^{\prime}(\cdot) \geq 0$, which solely depends on the level of $x$, the amount of aid per ill-individual received from donor countries $^{3} . \Delta$, hereafter referred as treatment's impact -on health-,can take any value between zero (treatment has no impact on the health condition of ill-individuals) and $\bar{\Delta}=h^{n s}-h^{s}$ (access to treatments increases the health condition of ill-individuals to that of healthy individuals, implying that there are no more productivity differentials in the economy). It is therefore perfectly equivalent, after taking into account the function $\delta(\cdot)$, to study the effect of variations in $x$ or in $\Delta$ on per capita production. We can rewrite equation [1] to express the first period's per capita production as a function of treatment's impact (and thus of $x$, the amount of aid per capita received):

$$
y_{[1]}(\Delta)=m f\left(h^{s}+\Delta\right)+(1-m) f\left(h^{n s}\right)
$$

\footnotetext{
${ }^{3} \delta(\cdot)$ transforms monetary amounts into health improvements through the purchase of medicines at exogenous market prices. All factors influencing the shape of $\delta(\cdot)$, including the responsiveness of health systems, healthcare infrastructures and workforce, or corruption, are considered fixed.
} 
In the second period, only a fraction of the first period's population survives. We denote by $\lambda_{i}$ the survival probability of individual $i$ that is determined by his/her health condition: $\lambda_{i}=\lambda\left(h_{i}\right) \in$ $[0,1]$, with $\lambda^{\prime}(\cdot)>0$. Period-2 per capita production is given by:

$$
y_{[2]}(\Delta)=\frac{m \cdot \lambda\left(h^{s}+\Delta\right) \cdot f\left(h^{s}+\Delta\right)+(1-m) \cdot \lambda\left(h^{n s}\right) \cdot f\left(h^{n s}\right)}{m \cdot \lambda\left(h^{s}+\Delta\right)+(1-m) \cdot \lambda\left(h^{n s}\right)}
$$

Since the share of ill individuals among the population is lower than in the first period, it is obvious that the survival process at work in this economy results in a (rather) spurious increase in per capita production between the two periods : $y_{[2]}(\Delta)>y_{[1]}(\Delta)$..More interestingly, the prevalence of the disease in the second period increases with $\Delta$ and thus with $x$. There is thus no guarantee that per capita production $y_{[2]}(\cdot)$ strictly increases with $\Delta$. Figure 1 presents two opposite cases, $y_{[2]}(\Delta) \gtrless y_{[2]}(\Delta=0)$. In the left panel, the availability of treatments increases both per capita health condition and per capita production. The right side figure highlights that a decrease in average health status is a necessary but not sufficient condition to observe a decrease of average production following the program's initiation.

\section{Insert Figure 1 here}

According to expression [5],: $y_{[2]}(\bar{\Delta})=f\left(h^{n s}\right)>y_{[2]}(\Delta=0)$. However, $y_{[2]}(\cdot)$ is not necessarily monotonously increasing in $\Delta$. As shown in the appendix, the slope of $y_{[2]}(\cdot)$ is negative if:

$$
e_{f / \lambda}(\Delta)=\frac{f^{\prime}\left(h^{s}+\Delta\right) / f\left(h^{s}+\Delta\right)}{\lambda^{\prime}\left(h^{s}+\Delta\right) / \lambda\left(h^{s}+\Delta\right)}<\frac{(1-m) \lambda\left(h^{n s}\right)}{m \lambda\left(h^{s}+\Delta\right)+(1-m) \lambda\left(h^{n s}\right)} \times \frac{f\left(h^{n s}\right)-f\left(h^{s}+\Delta\right)}{f\left(h^{s}+\Delta\right)}=c(\Delta)
$$

where $e_{f / \lambda}(\Delta)$ is the ratio of the health elasticity of production to that of survival, among the illpopulation, and where $c(\Delta)$ relates to the impact of changes in the population structure on production. It can be shown that the variation of $y_{[2]}(\cdot)$ with respect to $\Delta$ (and thus $x$ ) only depends on the sign of $e_{f / \lambda}(\Delta)-c(\Delta)$ for $\Delta=0$. 


\section{Proposition 1:}

If $e_{f / \lambda}(\Delta=0) \geq c(\Delta=0), y_{[2]}(\cdot)$ is a non-decreasing function of $\Delta, \forall \Delta \in[0, \bar{\Delta}]$.

In this case, the adverse epidemiological effect never exceeds the productive effect of treatments, and-from a per capita production maximization perspective-it's always worth implementing the treatment program.

\section{Proposition 2:}

If $e_{f / \lambda}(\Delta=0)<c(\Delta=0), y_{[2]}(\Delta)$ is strictly decreasing over an interval $\left[0, \Delta_{0}[\right.$, admits a unique minimizer $\Delta_{0}$ and increases within the interval $\left[\Delta_{0}, \bar{\Delta}\right]$, with $y_{[2]}(\bar{\Delta})>y_{[2]}(0)$.

\section{Corollary:}

If $e_{f / \lambda}(\Delta=0)<c(\Delta=0)$, there exists a unique value $\left.\tilde{\Delta} \in\right] \Delta_{0}, \bar{\Delta}[$ such that:

$$
\left\{\begin{array}{c}
y_{[2]}(\Delta)<y_{[2]}(0), \quad \forall \Delta \in[0, \tilde{\Delta}[ \\
y_{[2]}(\tilde{\Delta})=y^{2}(0) \\
\left.\left.y_{[2]}(\Delta)>y_{[2]}(0), \quad \forall \Delta \in\right] \tilde{\Delta}, \bar{\Delta}\right]
\end{array}\right.
$$

When the impact of the aid flow on the health condition of ill-individuals remains below a threshold $\tilde{\Delta}$, the adverse epidemiological effect exceeds the productive effects and the treatment policy has a detrimental effect on per capita production.

All things equal, a crucial element relates to the concavity of $f(\cdot)$ relative to $\lambda(\cdot)$ : when treatment expenditures increase the survival of ill-individuals by a larger rate than their production, inequality [6] is more likely to be satisfied. Some exogenous parameters $\left(m, h^{s}\right.$ and $\left.h^{n s}\right)$ can also impact both inequality [6] and the value of the threshold $\tilde{\Delta}$ (see proposition 3 and Figure 2 ).

\section{Proposition 3:}

$\tilde{\Delta}$ is a decreasing function of $m$ and $h^{s}$, and increases with $h^{n s}$ (see appendix). Besides, when the degree of concavity of $f(\cdot)$ increases, the pivotal level $\tilde{\Delta}$ decreases.

\section{Insert Figure 2 here}

Coming back to our initial research question, we actually substantiate by this two-periods model the puzzling result that for some ranges of improvements in individuals' health status $(\Delta)$, and 
hence for some corresponding levels of monetary investments $x$, the average production within the recipient country -its macroeconomic performance- is decreasing in the size of the healthcare program allocated to the population.

The integration of these non-trivial effects into econometric models is usually not carried out. It is difficult with aggregated data to obtain for a country chronological information on the following dimensions: 1) the composition of the population by health status 2 ) a clear decomposition of the various health programs targeting each sub-populations and 3) the productivity rates of these sub-populations (especially if the observation period should be long enough to capture and highlight the programs' impacts on the production-levels of people for all the relevant periods). Aggregated data are insufficient for effects measured "by nature" at the individual level (e.g. transition to illness, changes in survival and productivity rates), which are also conditioned by microeconomic behaviors, e.g. treatment adherence, efficiency of health services. Nevertheless the aggregated dimension is also important as part of the issue lies in the distribution between the ill and not-ill. In view of that, the microsimulation of individual trajectories using representative datasets is an attractive option to measure the effect of health programs on GDP.

\section{Discrete-Time Markov Model}

In economics, microsimulation methods are used to evaluate consequences of alternative policy decisions (tax policy, at the origin), both for individuals and for the whole society (Orcutt [1957], Citro and Hanushek [1991], Bourguignon and Spadaro [2003]). Microsimulation can be considered as a way of mimicking a natural experiment with the difference that outcomes are simulated instead of being observed following a policy shock. This methodology has been applied for the exante assessment of various reforms in the areas of tax policies and/or social policies (including health, see Abraham [2013]). In health sciences, microsimulation refers to a type of simulation modeling which generates individual life histories, generally health-status transitions (see Briggs and Sculpher [1998] for a review, and Arrighi, Abu Zaineh and Ventelou [2015], Cogneau and Grimm [2008], and Ventelou et al. [2012], for HIV application). We propose here a mix between 
these two approaches in order to evaluate the impact of treatment policies on the macroeconomics: from the medical perspective we borrow the idea that individuals' health trajectories can be virtually created (through a Markov process) under different scenarios of treatment procurement; from economics, we use the idea that aggregated effects can be captured by a microeconometric model. This mix enables us to examine, over the long run, the global effect of universal treatment campaigns on per capita GDP, taking into account both the individual and collective effects that the programs generate.

We propose to transpose the theoretical investigation examined in section 1 and 2 to the context of HIV programs using microsimulation techniques ${ }^{4}$. Without antiretroviral treatment (ART), HIV/AIDS considerably affects individual's survival chances and economic production. Antiretrovirals can transform HIV into a chronic condition and enable workers to recover (only) a certain level of productivity. The differential between the increases in survival and productivity raises the question of a potential lower macroeconomic performance following universal treatment procurement -what we called earlier the "adverse effect".

\section{Data Sources \& Aging Process}

The microsimulation model developed in Ventelou et al. [2012] enables forecasting, at the mid2030's horizon, the HIV status and life trajectories of representative agents under ART coverage rates ranging from 0 to $100 \%$. For the purpose of this paper, we use two hypothetical boundary scenarios, namely "No Access" (S1), a counterfactual without access to ART, and a "Universal Access" scenario (S2). We apply the microsimulation model to three representative datasets drawn from the Demographic and Health Surveys (DHS): the Tanzania HIV/AIDS Indicator Survey 2003-04 (THIS, $n=10,747$ individuals aged 15-49), the Cameroon Demographic and Health Survey 2004 (EDSC, $n=9,751$ ), and the Swaziland Demographic and Health Survey 2006-07 (SDHS,

\footnotetext{
${ }^{4} \mathrm{HIV} / \mathrm{AIDS}$ is not the only disease for which the adverse effect could be demonstrated. Besides, the microsimulation model -calibrated here for the case of HIV/AIDS by specific transition matrixes- could be used to study other chronic conditions (e.g. some cancers or cardiovascular diseases, etc..) The authors fully recognize that they did not try to follow these directions (the collection of epidemiological data is a huge entry-cost -already paid for HIV/AIDS).
} 
$n=8,187)$. These countries differ importantly in terms of HIV prevalence and situation on the labor market ${ }^{5}$. The surveys we selected precede the rapid scale up of treatment procurement over the last decade (UNAIDS [2004]).

An individual's future health status was forecasted using a discrete-time simulation model. In the model, an individual is, at a given period $t$, either HIV negative (HIV-), asymptomatic HIV (HIV+), symptomatic HIV requiring ARVs (HIV++) or deceased $(D)^{6}$. At the next period $t+1$ (one period lasting 5 years), the same person's health status is determined by an age and gender specific transition rate matrix according to that person's previous health status and access to ARVs. This Markovian process is represented by Figure 3.

\section{Insert Figure 3 here}

The DHS include three important components used to calibrate the model: HIV blood tests for interviewees aged 15-49, a sibling survivorship module (used to compute mortality rates), and the situation of the respondent on the labor market. These information were combined with WHO/UNAIDS estimates and results from the epidemiological literature to design the model. Full methodological details on the construction of the epidemiological dynamics can be found in Ventelou et al., 2012. Table 1 summarizes the key transition probabilities (to switch from HIV- to HIV+ $\left(\mathrm{P}_{01}\right)$, from HIV- to Death $\left(\mathrm{P}_{03}\right)$, from HIV+ to HIV++ $\left(\mathrm{P}_{12}\right)$, etc. $)$. Thanks to this explicit modeling of individual ageing, we can include the impact of access to ARVs on the future life histories of the populations. Zwahlen and Egger [2006] conducted a literature review on the time from ART eligibility (2006 guidelines) to death by AIDS in developing countries. The study indicates a median survival after AIDS or after CD4 cell counts drop below 200 cells/ $\mu$ l scatter around 1 year. For simplicity (but rather sadly realistically), we assume in the baseline analysis that all HIV++

\footnotetext{
${ }^{5}$ HIV prevalence is $5 \%$ in Cameroon, $6 \%$ in Tanzania and $26 \%$ in Swaziland. Per capita GDP ranges from $700 \$$ in Tanzania to $4460 \$$ in Swaziland.

${ }^{6}$ The partition of the HIV positive population is based on 2006 WHO guidelines for ART initiation: HIV++ individuals include PLWHIV in stages I or II with CD4-cell counts $\leq 200$ cells/ $\mu$, in stage III with a CD4 count $\leq 350 / \mu l$, and in stage IV, regardless of CD4 count. More recent and less restrictive guidelines, designed to serve as a preventative tool (see further paragraph), could have been applied in this paper. Yet, HIV+ (2006 guidelines) and HIV-groups do not exhibit large differences in survival and productivity, so that the choice of the guideline has little implications on our results.
} 
individuals who do not receive ARVs systematically decease over five years $\left(P_{23}=1\right.$, i.e. $h^{s}=$ $\left.1-\mathrm{P}_{23}=0\right)$. In case of access to treatment, the survival probability of the HIV++ population raises from zero to $\Delta=\mathrm{P}_{03}-u$, i.e. $h^{s}+\Delta=h^{n s}-u$ for analogy with the theoretical framework. In the context of 2006 eligibility criteria, Etard [2006] and Leger [2009] document a survival rate of $75 \%$ five years after ART initiation. In line with this literature, we fix $u$ at 0.2 for the baseline analysis (see Table 1).

ARV procurement policies may also result in a reduction of the spread of the epidemic when a large proportion of the infected population is under ART, as ARV limits patient's infectiousness during sexual intercourses (see e.g. Granich et al. [2009]). In S2, this effect is not included. Two additional versions of scenario $S 2$, namely $S 2 M$ and $S 2 H$, were created in order to take into account any new possible deformation of the transition matrix (in $\mathrm{P}_{01}$ and $\mathrm{P}_{02}$ ) arising from different assumptions regarding the strength of this preventative effect: the probability of seroconversion is reduced by $20 \%$ in S2M and by $50 \%$ in $\mathrm{S} 2 \mathrm{H}$.

\section{Economic Outcomes}

The HIV-Aids crisis has a direct link with economic outcomes: AIDS deaths lead mechanically to a reduction in the number of available workers. These deaths occur principally among workers in their most productive years (Table 1). Access to ARV drugs counteracts this first impact, by reducing mortality. In parallel, ARV drugs have an additional impact on economic outcomes through a secondary channel, occurring during the lifetime of the HIV infected population (and not after their death), by increasing the productivity of the numbers of hours worked. We compute individual incomes in the microsimulation model by taking the products between 1) age and gender specific rates of participation to the labor market, estimated on the DHS; 2) health status specific productivity rates, taken from the literature; and 3) the maximal average income on the basis of full-time employment (computed from aggregated international data).

The standardized DHS questionnaire includes a module on respondents' employment status. Respondents were asked whether they were working in the 7 days preceding the interview. We regress the probability to participate to the labor market (formal and informal) on respondent's 
age class and gender using a binary logit model. The parameters' estimates are presented in appendix. In the three countries, employment rate is increasing with age -at a decreasing rateand is higher among men than among women. We did not include HIV status as a determinant of employment in the regression, because our cross-sectional data does not offer the possibility to account for the endogenous relationship between HIV status and employment (for instance, in Cameroon and Swaziland (not in Tanzania), being HIV positive is positively correlated with both household wealth and employment, e.g. due to reverse causality or to the existence of a hidden common factor).

We thus capture the microeconomic effect of HIV through variations in productivity rates. Fox et al. (2004) analyze data from a Kenyan tea estate and observe a decrease of $17.7 \%$ in the earnings of untreated HIV puckers the year before they died or medically retired. To our knowledge, there is no other experimental longitudinal study focusing on untreated HIV+ workers (for obvious ethical reasons). The consequences of ART initiation on labor supply were extensively examined by recent studies (Habyarimana et al. [2010], Kyereh \& Hoffman [2008], Larson et al. [2008], Thirumurthy et al. [2008], Thirumurthy and Graff Zivin [2012]). ART initiation is found to achieve rapid and important -yet imperfect- restoration of productivity over up to 4-years. From this literature, we set the productivity loss of untreated HIV++ workers at $25 \%$, lowering to $10 \%$ after ART initiation. We found no studies focusing on the particular group of workers whose HIV stage does not meet 2006 eligibility criteria. For simplicity, and because of a lack of literature on people in the asymptomatic stage of HIV (HIV+ state), we let HIV- and HIV+ agents experience full productivity rates in the microsimulation model.

The "maximal average income per working adult (at full productivity rate)" is the national gross GDP per working adult aged 15-49 (refer to Appendix for values). This measure is supposed to take into account all other production factors available in the economy at the beginning of the micro-simulation process.

Aggregate GDP levels are then computed by aggregating individual wages, accounting for the representative weight of each observation, i.e. the number of "real" agents one DHS interviewee 
represents. GDP dynamics are endogenously determined in the microsimulation model by epidemiologic and demographic changes (while other factors are supposed exogenous and invariant over time). No exogenous GDP growth rate is included (a conservative assumption).

\section{Evaluating the 'Adverse Effect' using the Micro-Simulation Model}

The micro-simulation model can also help to evaluate the magnitude of the "adverse effect" as defined in the theoretical framework. We can simplify equation [3] with $\frac{\partial h^{n s}}{\partial x}=0$ (meaning that access to ART does not improve nor deteriorate the health status of those HIV negative). ${ }^{7}$ We can also specify the productivity gap between ill and non-ill agents, with a production loss per treated worker set to $v=\frac{f\left(h^{n s}\right)-f\left(h^{s}\right)}{f\left(h^{n s}\right)}=10 \%$. Equation [3] becomes:

$$
\mathrm{d} y(v)=m \cdot \frac{\partial h^{s}}{\partial x} \cdot \frac{\partial f\left(h^{s}\right)}{\partial h^{s}} \mathrm{~d} x-v \cdot f\left(h^{n s}\right) \cdot \frac{\partial m}{\partial x} \mathrm{~d} x
$$

The two parts of the equation provide the decomposition between the "full" positive effect of S2 and the negative composition effect due to an increase in prevalence rate. The difficulty with discrete time data is that it is not possible to relate observed changes in $m$ (prevalence) with $\mathrm{d} x$ (changes in the level of health expenditures) and this for multiple periods (forecasts of $m$ for each scenario diverge after the first period). A feasible method is then to observe the output of the model assuming $v=0$, which is a way of measuring the GDP gain as if the adverse epidemiological effect did not exist, i.e. as if ARVs enabled treated workers to be as productive as their HIV negative counterparts (in this case, the increase of prevalence and the change in the labor force structure has no detrimental impact on the economy). This is now a common use of micro-simulation models to include a "virtual case" (with null value assigned to given parameters) in order to decompose observed disparities into their various probable sources (see for ex.

\footnotetext{
${ }^{7}$ As in the theoretical model, the production function used in the microsimulation exhibits perfect substitutability between working time of healthy worker and unhealthy worker. However, if it involved more complementarity between workers, it could be the case that providing care to a given person also raises the productivity of other (untreated) workers. A broader question raised by this kind of exercise is to know how robust it is to the underlying postulated production function. Note that ignoring complementarities may lead to underestimate the positive impact of health programs on overall productivity.
} 
analysis of healthcare use inequalities in Huber [2008] and Abu-Zaineh et al. [2010]). We define $\mathrm{d} y^{*}$ such that:

$$
\mathrm{d} y^{*}=\mathrm{d} y[v=0]=m \cdot \frac{\partial h^{s}}{\partial x} \cdot f^{\prime}\left(h^{s}\right) \cdot \mathrm{d} x
$$

The difference $\mathrm{d} y^{*}-\mathrm{d} y(v)=v \cdot f\left(h^{n s}\right) \cdot \frac{\partial m}{\partial x} \mathrm{~d} x$ precisely measures the size of the adverse effect. The change in per capita earnings from S1 (no access) to S2 (universal access) is:

$$
y_{S 2}(v)-y_{S 1}(v)=\underbrace{\left[y_{S 2}^{*}(v=0)-y_{S 1}(v)\right]}_{\text {Full Effect }}-\underbrace{\left[y_{S 2}^{*}(v=0)-y_{S 2}(v)\right]}_{\text {Adverse Effect }}
$$

\section{Main Results}

\section{Insert Table 2 here}

Table 2 presents simulated life paths from an arbitrary selection of individuals from the Tanzanian DHS 2003-04 Survey. At every period (2009... 2034) an individual is characterized by his/her health status (column $\mathrm{H}$ ), whether or not he/she receives ARV (when eligible, column T) and his/her annual wage (column w). The model yields (probable) individual health trajectories and associated earnings, for the no-access and universal access scenarios, with and without the adverse effect. It enables computing differentials in economic product, either for each individual (2009/2038 column) or for each period (GDP Gap Line), and thus estimating the magnitude of the epidemiological adverse effect in this micro-society.

For example, individual 116 is a HIV- male aged 20-24 earning \$3,580 during 2009-2014. He contracts HIV in the same period and becomes eligible to ART during 2024-29. Had he received ARVs, he survives until the end of the simulation. Over the entire simulation process, this individual ears $\$ 8,075$ more in $S 2$ than in $\$ 1$. However, this gain could reach $\$ 9,325$ if the adverse effect did not exist. Other individual trajectories are discussed in the footnote of Table 2. From a cross-sectional perspective (last line of Table 2), S2 generates increases in aggregate GDP (gains range from $\$ 585$ to $\$ 10,350)$. However, these increases in total amounts do not always imply improvements in per capita terms: in the $2010 / 2018$ period, per capita GDP is $\$ 125$ lower in S2 than in S1 (the adverse effect exceeds the productive effects of ART). 


\section{Insert Table 3 here}

The increase in survival rates among the HIV++ population following ART initiation generates radical changes in the epidemiological and demographic patterns of the three countries, compared with the No Access scenario. The number of HIV++ individuals sharply increases over time (increasing the share of the population requiring ART), and the number of deaths is considerably lower. Similar observations can be made regarding the evolution of HIV prevalence (Figure 4). Providing universal treatment transforms HIV into a chronic condition which becomes increasingly prevalent in the population (Figure 4). Inversely, without ART (S1), HIV prevalence decreases over time as a consequence of wide-scale death among the HIV++ population.

\section{Insert Figures 4 \& 5 here}

The universal access scenario 52 enables more human lives to be saved than the No Access scenario, and the lives saved have a positive economic production contributing towards an increase in aggregate GDP levels in all three countries. In Cameroon, total GDP under S2 exceeds that of S1 by 3.59 billion USD (+1.8\%, Table 3) during the $2034 / 2039$ period and by 13.71 USD billion (+1.45\%) over the whole simulation process. Similar results were found in Tanzania and Swaziland. We find that these increases in aggregate GDP are sufficiently large to generate gains also in per capita terms, in all three countries and for each simulation period (Figure 5). In the case of HIV programs, the adverse effect is not found to exceed the productive effects of ARVs, at least in the three countries under consideration. Per capita GDP gains range from $0.04 \%$ in Cameroon to $1.67 \%$ in Swaziland in the initial period, increase and then stagnate. At the end of the simulation, per capita annual earnings increased by $0.41 \%$ in Cameroon, by $0.27 \%$ in Tanzania and by $2.51 \%$ in Swaziland.

\section{Insert Figure 6 here}

The gains in per capita GDP induced by universal access to ARVs are subject to the adverse effect, as HIV is transformed into a chronic condition. This adverse effect is shown to affect considerably the economic consequences of the treatment program. In Swaziland, at the end of the simulation, annual per capita GDP is $\$ 5,028$ for $S 2$, but could reach $\$ 5,108$ in the absence of an adverse effect 
(Table 3). In this example, the adverse effect prevents an additional $1.6 \%$ growth of per capita GDP. Figure 6 summarizes the magnitude of the adverse effect relative to the full effect of the programs (i.e. for $v=0$ ) and suggests a moderately increasing trend. In the presence of the adverse effect, the Universal Access programs merely achieve $60 \%$ of their potential impacts in Cameroon and Swaziland (Figure 6). In Tanzania, the adverse effect shrinks the gains in per capita GDP by $42 \%$ in 2009 and by $54 \%$ in 2034 (Figure 6).

\section{The preventative effect of ART}

Previous results do not take into account the fact that when a large proportion of the population is treated with ARVs, the spread of the HIV epidemic might decrease (Granich et al. [2009]). The impact of this hypothesis on HIV prevalence is illustrated by $\mathrm{S} 2 \mathrm{H}$ and S2M in Figure 2. If a small reduction in incidence rates is assumed (S2M, probabilities of seroconversion $P_{01}$ are multiplied by factor 0.80 ), the prevalence rates decrease over time and exceed only slightly those associated with the no-access scenario at the end of the simulation process. HIV prevalence can even become lower than that of $\mathrm{S} 1$ after two simulation periods (10 years), when a $50 \%$ reduction in seroconversion rates is assumed ( $\mathrm{S} 2 \mathrm{H}$, Figure 2). GDP levels for these two variants are higher than in S2, and these extra gains tend to increase over time as the preventative effect of ART has a multiplicative effect on seroconversion. At the end of the simulation process, gains in per capita GDP reach 70 (in Tanzania) to 85\% (in Swaziland) of their potential levels in the absence of the adverse epidemiological effect (Figure 4). 


\section{Discussion}

This paper investigates the relationship between public spending on the health sector and economic performances. It can be included in an increasing list of studies evaluating the effect of (better) health on macroeconomic performances, that is to say, its long term GDP growth rate (Acemoglu and Johnson [2007], Weil [2007, 2010]). This literature was revived by the publication of the WHO report in 2001, which suggested that investment in health is a key step in macroeconomic development. Nevertheless, we add a dimension: our work shows the importance of an epidemiological effect, which attenuates the economic impact of programs enhancing access to healthcare in developing countries.

Treatment policies include, by their very nature, an adverse effect which could cancel out or even overwhelm their positive impact on economic outcomes expressed in per capita terms. Following the availability of ART, HIV positive individuals experience improved survival conditions and HIV becomes a chronic condition. Without medicines guaranteeing a sufficient increase in productivity, healthcare programs might be economically counterproductive. However, it is not easy to precisely quantify this composition effect, as in order to do so, one would need the "counter-factual" epidemiological evolution for each program evaluated (that is to say, the evolution if the program never existed). To answer the question thoroughly, we used a Markovian micro-simulation model to quantify both the epidemiological impact and the adverse effect of ART programs. We showed that despite a rather large adverse effect (ranging between $40 \%$ and $54 \%$ of their potential economic impacts), universal ART programs lead to gains in per capita GDP, compared with the situation without procurement of ARVs. That said, these results, showing the existence of the adverse effect, in no way constitute a valid reason to recommend not implementing such healthcare programs: one can decide to implement life-saving programs even if their net economic benefit proves to be negative. Putting it simply, there is a "price of human life", which societies may want to pay, for reasons other than financial (i.e. ethical reasons).

In a more general point of view, these analyses draw attention to the difficulties that arise when evaluating some sets of policies which, in their very nature, implicate changes in the composition and size of the populations. When lives are in questions, the welfare criterions used for policy 
evaluation must be selected with caution. In another context (the case of new-borns), Derek Parfit [1984] presents a puzzle that, in a nutshell, runs as follows: (i) using total utilitarianism, a population with a significant number of individuals enjoying lives of very high quality would be inferior to a population with an enormously greater number of people whose lives are barely worth living (the Repugnant Conclusion), and (ii) using average utilitarianism, a population composed of few lives of exceptional quality would be superior to a population of a billion lives whose quality is just slightly lower (the Mere Addition paradox). This later paradox can be translated in our example of HIV-treatment procurement, because such curative programs change the number of surviving individuals ${ }^{8}$, whose existence can critically affect metrics based on average utilitarianism (for instance GDP per capita) and the level of healthcare intervention the policy-maker should be tempted to select. This discussion is particularly relevant when preventive and curative programs are competing. The two strategies imply various effects on welfare metrics, including the adverse effect for the curative option that this paper emphasizes, although both clearly have their limitations. Future steps of the research should consist in finding a welfare indicator which would be robust to population size changes, and determining an ("optimal") level of spending for both the preventive and the curative strategies.

Finally, the limitations of our results need to be highlighted: the evaluations carried out in the micro-simulation obviously depend on certain inputs introduced into the model. The epidemiological dynamics (raw transition probabilities) are relatively robust when one takes into account the sources used and their exogeneity with respect to the macroeconomic problems treated here (UNAIDS data, data from medical literature). On the other hand, the parameters introduced to quantify productivity are more fragile. We did not test the sensitivity of our results to the productivity differentials between the different groups composing the population. Following the literature, we set the (relative) productivity loss of treated workers at $10 \%$. This figure of $10 \%$ is probably overestimating the true productivity-loss of PLWHIV under new antiretroviral-drug, even if there is no scientific evidence of any recent figures for developing

\footnotetext{
${ }^{8}$ even if they don't create additional lives as in Parfit's work.
} 
countries (in Europe, it has been shown that ability to work of PLWHIV improves with the availability of new therapies, which are easier to take - Elzi et al. [2016]). It seemed to us that this overestimation was conservative, supplying an upward-biased estimate of the magnitude of the adverse effect. 


\section{REFERENCES}

ABRAHAM J.M. [2013], Using Microsimulation Models to Inform U.S. Health Policy Making. Health Services Research, 48, 686-695.

ABU-ZAINEH M., MATARIA A., MOATTI J.P., VENTELOU B. [2010], Measuring and decomposing socioeconomic inequality in healthcare delivery: A microsimulation approach with application to the Palestinian conflict-affected fragile setting, Social Sciences and Medicine, 72 (2), 133-41.

ACEMOGLU D., JOHNSON S. [2007], Disease and Development: the Effect of Life Expectancy on Economic Growth. Journal of Political Economy, 115 (6), 925-985.

ARRIGHI Y., ABU ZAINEH M., VENTELOU B. [2015], To count or not to count deaths: reranking effects in health distribution evaluation. Health Economics, 24, 193-205.

BELL C., DEVARAJAN S., GERSBACH H. [2003], The Long-Run Economic Costs of AIDS: Theory and an Application to South Africa. World Bank economic Review, 20 (1), 55-89.

BLOOM D.E., CANNING D. [2000], The health and wealth of nations. Science, 287 (5456), 1207-1209.

BLOOM D.E., CANNING D., SEVILLA J. [2004], The Effect of Health on Economic Growth: A production Function Approach. World Development 32 (1), 1-13.

BOURGUIGNON F.J., SPADARO, A. [2006], Microsimulation as a tool for evaluating redistribution policies. Journal of Economic Inequality 4(1), 77-106.

BRIGGS A., SCULPHER M. [1998], An introduction to Markov modelling for economic evaluation. Pharmacoeconomics 13 (4), 397-409.

CITRO C., HANUSHEK E. [1991], "Improving information for social policy decisions: the uses of microsimulation modelling". National Academy Press, Washington.

COGNEAU D., GRIMM M. [2008], The impact of AIDS mortality on the distribution of income in Côte d'Ivoire. Journal of African Economies 17 (5), 688-728.

ELZI, L., CONEN, A., PATZEN, A., FEHR, J., CAVASSINI, M., CALMY, A., BATTEGAY, M. [2016], Ability to work and employment rates in human immunodeficiency virus (HIV)-1-infected individuals receiving combination antiretroviral therapy: the Swiss HIV Cohort Study. Open forum infectious diseases, 3(1).

ETARD J.F., NDIAYE I., THIERRY-MIEG M., GUEYE N.F. and GUEYE P.M. [2006], Mortality and causes of death in adults receiving highly active antiretroviral therapy in Senegal: a 7-year cohort study. AIDS 20, 1181-1189.

FOGEL R.W. [1993], The Escape from Hunger and Premature Death, 1700-2100: Europe, America, and the Third World. Cambridge University Press.

FOX M.P., ROSEN S., MACLEOD W.B., WASUNNA M., BII M., FOGLIA G., SIMON J.L. [2004], The impact of HIV/AIDS on labor productivity in Kenya. Tropical Medicine \& International Health, 9 (3), 318-324.

GRANICH R.M. GILKS C., DYE C., DE COCK K., WILLIAMS B. [2009], Universal voluntary HIV testing with immediate antiretroviral therapy as a strategy for elimination of HIV transmission: a mathematical model. The Lancet 373 (9657), 48-57.

HABYARIMANA J., MBAKILE B., POP-ELECHES C. [2010], The Impact of HIV/AIDS and ARV Treatment on Worker Absenteeism: Implications for African Firms. Journal of Human Resources 45 (4), 809-839.

HOLLAND J.H., MILLER J.H. [1991], Artificial Adaptive Agents in Economic Theory. American Economic Review 81 (2), 365-71. 
HUBER H. [2008], Decomposing the causes of inequalities in health care use: a micro-simulations approach. Journal of Health Economics 27 (6), 1605-13.

KANBUR R. MUKHERJEE D. [2007], Premature Mortality and poverty measurement. Bulletin of Economic Research 59 (4), 339-359.

KYEREH K.T. HOFFMAN D.J. [2008], The Impact of HIV/AIDS on Skills availability in South African Coal Mines. Dublin Conference on Children affected by HIV/AIDS. Unpublished.

LARSEN B.A., FOX M.P., ROSEN S., BII M., SIGEI C., SHAFFER D., SAWE F., WASUNNA M., SIMON, J.L. [2008], Early effects of antiretroviral therapy on work performance: preliminary results from a cohort study of Kenyan agricultural workers. AIDS 22(3), 421-425.

LEGER P., CHARLES M., SEVERE P., RIVIERE C., PAPE J.W., FITZGERALD D.W. [2009], 5-year survival of patients with AIDS receiving antiretroviral therapy in Haiti. New England Journal of Medicine 361, 828-829.

LEFÈBVRE M., PESTIEAU P., PONTHIÈRE G. [2013], Measuring poverty without the mortality paradox. Social Choice and Welfare, 40(1), 285-316.

LEFÈBVRE M., PESTIEAU P., PONTHIÈRE G. [2018], FGT old-age poverty measures and the mortality paradox: theory and evidence. Review of Income and Wealth, 64, 428-458.

ORCUTT G.H. [1957], A New Type of Socio-Economic System. Review of Economics and Statistics 58, $773-797$.

PARFIT D. [1984], Reasons and persons. Oxford: Clarendon Press.

SCHULTZ T.P. [2010], Health Human Capital and Economic Development. Journal of African Economies 19(3), 12-80.

SMITH R.D., YAGO M., MILLAR M., COAST J. [2005], Assessing the macroeconomic impact of a healthcare problem: The application of computable general equilibrium analysis to antimicrobial resistance. Journal of Health Economics 24 (6), 1055-1075.

THIRUMURTHY H., GRAFF ZIVIN J., GOLDSTEIN M. [2008], The Economic Impact of AIDS Treatment: Labor Supply in Western Kenya. Journal of Human Resources 43 (3), 511-552.

THIRUMURTHY H., GRAFF ZIVIN J. [2012], Health and labor supply in the context of HIV/AIDS: the long-run economic impacts on antiretroviral therapy. Economic Development and Cultural Change 61(1), 73-96.

UNAIDS/WHO [2004], Epidemiological Fact Sheets on HIV/AIDS and Sexually Transmitted Infections, 2004 Update.

VENTELOU B., ARRIGHI Y., GREENER R., LAMONTAGNE E., CARRIERI P.M., MOATTI, J.P. [2012], The macroeconomic consequences of renouncing to universal access to antiretroviral treatment for HIV in Africa. PLoS-ONE, 7(4), e34101.

WEIL D.N. [2007], Accounting for the Effect of Health on Economic Growth. Quarterly Journal of Economics 122(3), 1265-1306.

WEIL D.N. [2010], Endemic Diseases and African Economic Growth: Challenges and Policy Responses. Journal of African Economies, 19 (3), 81-109.

WHO [2001], Macroeconomics and health: investing in health for economic development, Report of the Commission on Macroeconomics and Health. Geneva.

WHO [2018], Global Health Estimates 2016: Deaths by Cause, Age, Sex, by Country and by Region, $2000-2016$. Geneva.

ZWAHLEN M., EGGER M. [2006], Progression and mortality of untreated HIV-positive individuals living in resourcelimited settings: Update of Literature review and evidence synthesis. 


\section{Figure 1: Opposite effects of the treatment programs}
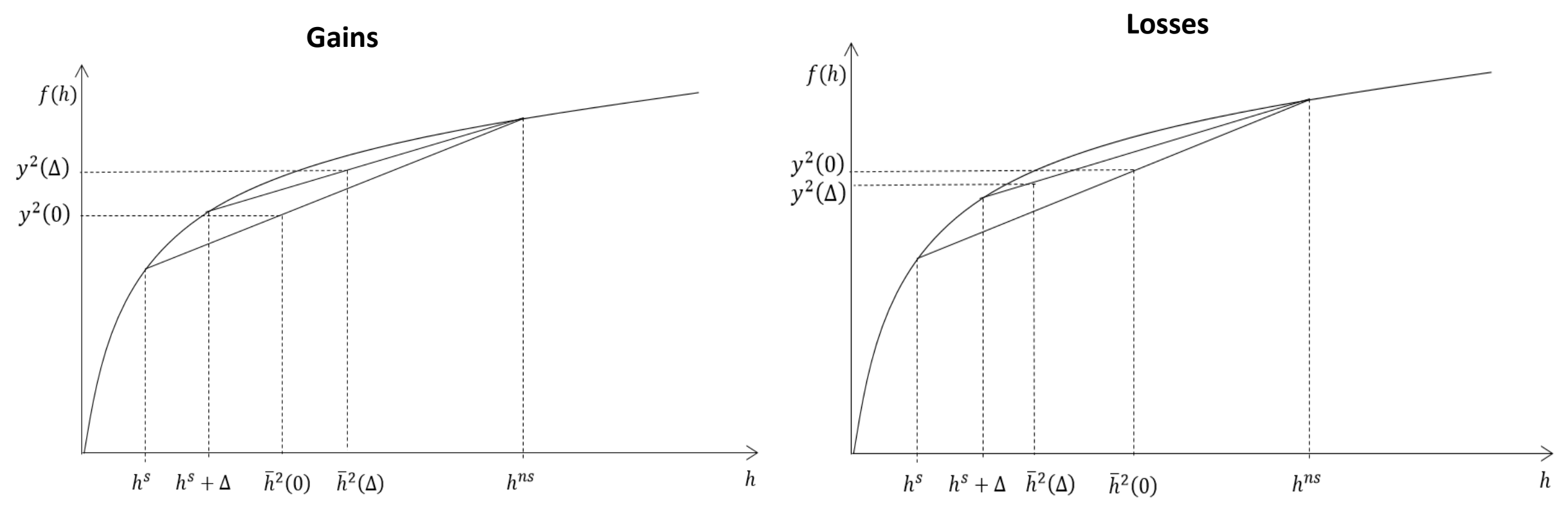

\section{Lecture note:}

$\bar{h}^{2}(\Delta)$ denotes the average health condition of the population, expressed as a function of treatment's impact:

$$
\bar{h}^{2}(\Delta)=\frac{m \cdot \lambda\left(h^{s}+\Delta\right) \cdot\left(h^{s}+\Delta\right)+(1-m) \cdot \lambda\left(h^{n s}\right) \cdot h^{n s}}{m \cdot \lambda\left(h^{s}+\Delta\right)+(1-m) \cdot \lambda\left(h^{n s}\right)}
$$




\section{Figure 2: Illustrations of proposition 3}

Lecture note: treatment effect $\Delta$ on horizontal axis; per capita GDP in the second period $y_{[2]}(\Delta)$ on vertical axis

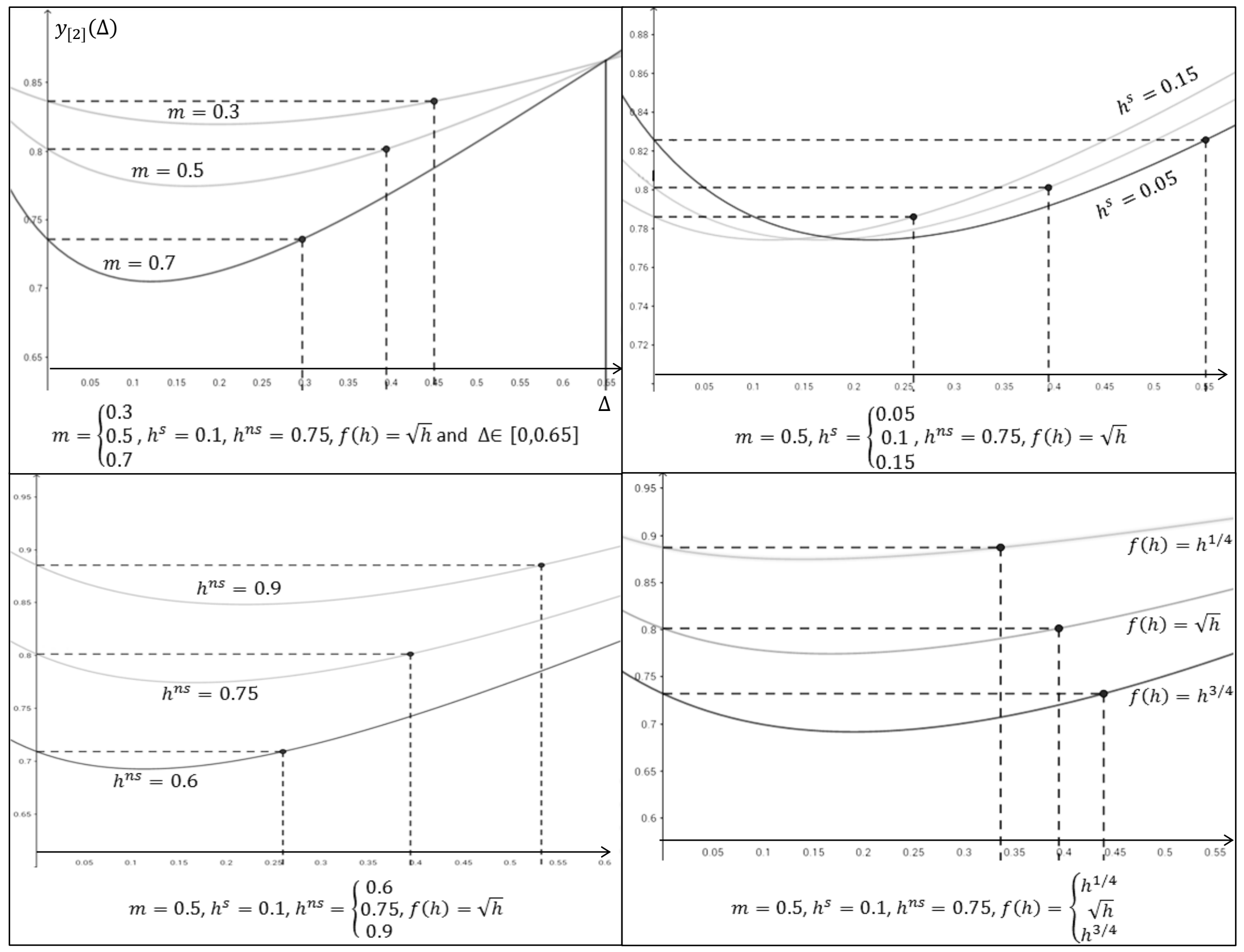




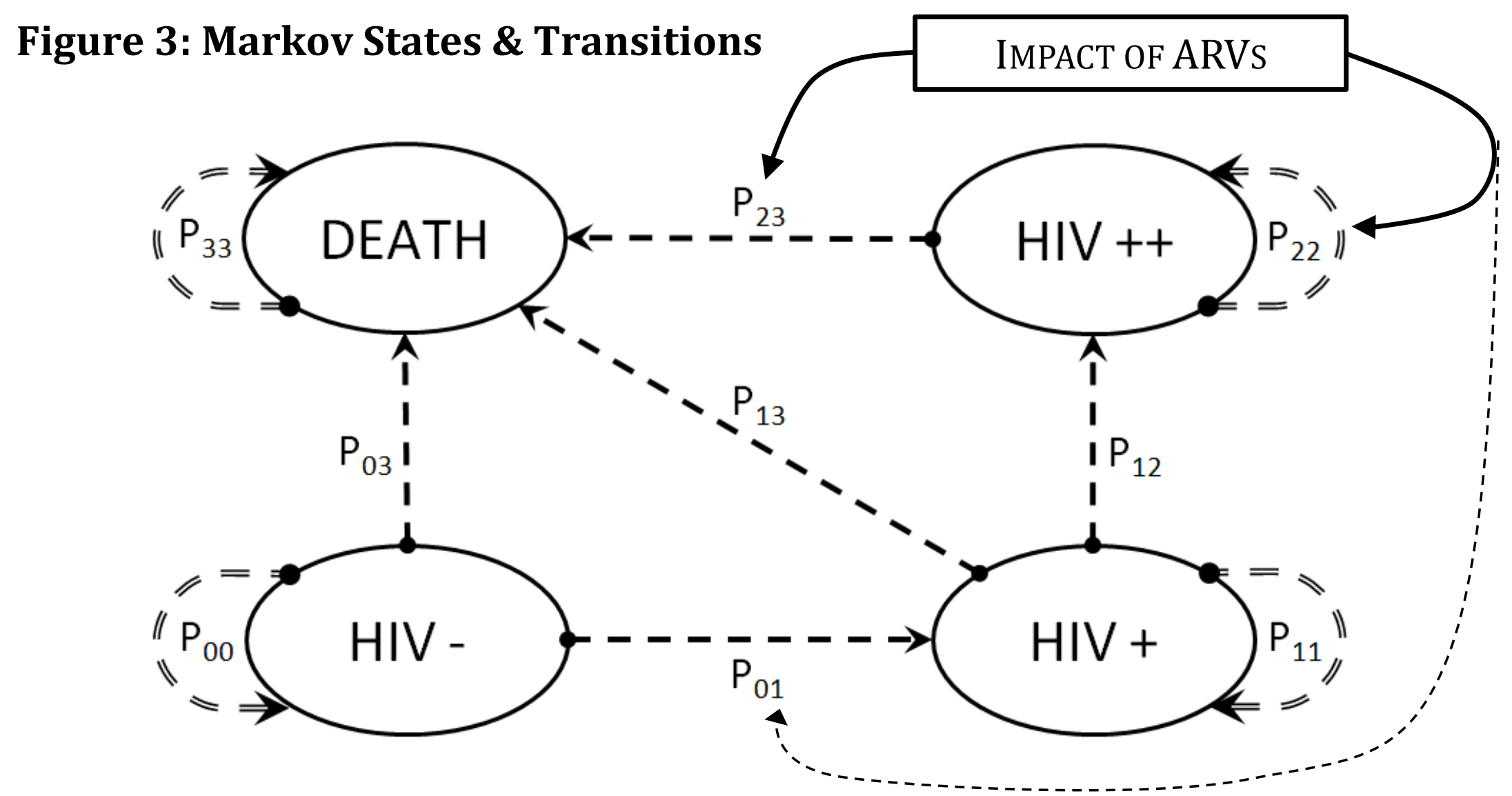

\section{Lecture note:}

Since there is no remission from HIV, $\mathrm{P}_{10}=\mathrm{P}_{20}=\mathrm{P}_{21}=0$.

We assume $\mathrm{P}_{02}=0$ : a sero-negative individual cannot contract HIV and progress to the symptomatic stage within 5 years.

We also have $\mathrm{P}_{00}=1-\mathrm{P}_{01}-\mathrm{P}_{03} ; \mathrm{P}_{11}=1-\mathrm{P}_{12}-\mathrm{P}_{13} ; \mathrm{P}_{22}=1-\mathrm{P}_{23}$ 


\section{Table 1: Transition Rates}

\begin{tabular}{|c|c|c|c|c|c|c|c|c|c|c|c|c|c|c|c|c|c|}
\hline \multirow{3}{*}{ Country } & \multirow{3}{*}{ Age } & \multicolumn{4}{|c|}{ DHS Data } & \multicolumn{12}{|c|}{ Computed Rates } \\
\hline & & \multicolumn{2}{|c|}{ HIV Prevalence } & \multicolumn{2}{|c|}{$\begin{array}{c}\text { 5yrs } \\
\text { Mortality rate }\end{array}$} & \multicolumn{2}{|c|}{ \% Eligible to ART } & \multicolumn{2}{|c|}{$\begin{array}{c}P_{01} \\
\text { (HIV- to HIV+) }\end{array}$} & \multicolumn{2}{|c|}{$\begin{array}{c}P_{03} \\
\text { (HIV- to Death) }\end{array}$} & \multicolumn{2}{|c|}{$\begin{array}{c}P_{12} \\
\text { (HIV+ to HIV++) }\end{array}$} & \multicolumn{2}{|c|}{$\begin{array}{c}\mathrm{P}_{13} \\
\text { (HIV+ to Death) }\end{array}$} & \multicolumn{2}{|c|}{$\begin{array}{c}P_{23} \\
\text { (HIV++ ART to } \\
\text { Death) }\end{array}$} \\
\hline & & $\mathrm{M}$ & $\mathrm{F}$ & M & $\mathrm{F}$ & M & $\mathrm{F}$ & $M$ & $\mathrm{~F}$ & $M$ & $\mathrm{~F}$ & $M$ & $\mathrm{~F}$ & $M$ & $\mathrm{~F}$ & $M$ & $\mathrm{~F}$ \\
\hline \multirow{7}{*}{ 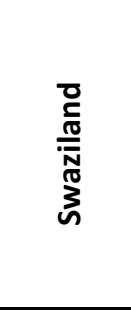 } & $15-19$ & $1.87 \%$ & $10.07 \%$ & $1.10 \%$ & $2.03 \%$ & $22.76 \%$ & $24.32 \%$ & $4.79 \%$ & $14.57 \%$ & $0.81 \%$ & $0.38 \%$ & $32.55 \%$ & $34.78 \%$ & $1.31 \%$ & $0.88 \%$ & $20.81 \%$ & $20.38 \%$ \\
\hline & $20-24$ & $12.34 \%$ & $38.41 \%$ & $2.82 \%$ & $5.81 \%$ & $25.04 \%$ & $26.75 \%$ & $10.42 \%$ & $17.99 \%$ & $0.74 \%$ & $0 \% *$ & $35.80 \%$ & $38.25 \%$ & $1.24 \%$ & $0 \% *$ & $20.74 \%$ & $18.81 \%$ \\
\hline & $25-29$ & $27.76 \%$ & $49.20 \%$ & $5.91 \%$ & $9.84 \%$ & $27.54 \%$ & $29.43 \%$ & $15.80 \%$ & $15.85 \%$ & $0.79 \%$ & $0.10 \%$ & $39.38 \%$ & $42.08 \%$ & $1.29 \%$ & $0.60 \%$ & $20.79 \%$ & $20.10 \%$ \\
\hline & $30-34$ & $43.75 \%$ & $45.24 \%$ & $10.62 \%$ & $8.68 \%$ & $30.29 \%$ & $32.37 \%$ & $15.51 \%$ & $12.58 \%$ & $1.85 \%$ & $0 \% *$ & $43.32 \%$ & $46.29 \%$ & $2.35 \%$ & $0 \% *$ & $21.85 \%$ & $18.74 \%$ \\
\hline & $35-39$ & $44.92 \%$ & $37.72 \%$ & $11.53 \%$ & $10.44 \%$ & $33.32 \%$ & $35.61 \%$ & $13.35 \%$ & $8.78 \%$ & $1.62 \%$ & $1.56 \%$ & $47.65 \%$ & $50.92 \%$ & $2.12 \%$ & $2.06 \%$ & $21.62 \%$ & $21.56 \%$ \\
\hline & $40-45$ & $40.68 \%$ & $27.87 \%$ & $15.23 \%$ & $9.47 \%$ & $36.65 \%$ & $39.17 \%$ & $8.61 \%$ & $6.31 \%$ & $5.74 \%$ & $2.32 \%$ & $52.42 \%$ & $56.01 \%$ & $6.24 \%$ & $2.82 \%$ & $25.74 \%$ & $22.32 \%$ \\
\hline & $45-49$ & $27.86 \%$ & $21.42 \%$ & $17.18 \%$ & $10.76 \%$ & $40.32 \%$ & $43.08 \%$ & $8.03 \%$ & $5.84 \%$ & $10.34 \%$ & $4.85 \%$ & $57.66 \%$ & $61.61 \%$ & $10.84 \%$ & $5.35 \%$ & $30.34 \%$ & $24.85 \%$ \\
\hline \multirow{7}{*}{ 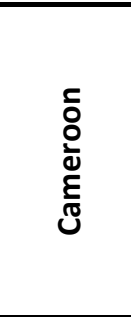 } & $15-19$ & $0.62 \%$ & $2.13 \%$ & $1.50 \%$ & $1.49 \%$ & $22.11 \%$ & $23.44 \%$ & $0.98 \%$ & $2.83 \%$ & $1.31 \%$ & $1.02 \%$ & $31.92 \%$ & $33.84 \%$ & $1.81 \%$ & $1.52 \%$ & $21.31 \%$ & $21.02 \%$ \\
\hline & $20-24$ & $2.54 \%$ & $7.48 \%$ & $2.03 \%$ & $2.60 \%$ & $24.32 \%$ & $25.79 \%$ & $1.92 \%$ & $3.75 \%$ & $1.62 \%$ & $0.79 \%$ & $35.11 \%$ & $37.23 \%$ & $2.12 \%$ & $1.29 \%$ & $21.62 \%$ & $20.79 \%$ \\
\hline & $25-29$ & $5.14 \%$ & $10.28 \%$ & $3.06 \%$ & $3.86 \%$ & $26.75 \%$ & $28.37 \%$ & $2.91 \%$ & $3.38 \%$ & $1.79 \%$ & $0.60 \%$ & $38.62 \%$ & $40.95 \%$ & $2.29 \%$ & $1.10 \%$ & $21.79 \%$ & $20.60 \%$ \\
\hline & $30-34$ & $8.10 \%$ & $9.66 \%$ & $3.87 \%$ & $3.99 \%$ & $29.43 \%$ & $31.20 \%$ & $2.96 \%$ & $2.42 \%$ & $1.87 \%$ & $0.97 \%$ & $42.48 \%$ & $45.04 \%$ & $2.37 \%$ & $1.47 \%$ & $21.87 \%$ & $20.97 \%$ \\
\hline & $35-39$ & $8.60 \%$ & $7.26 \%$ & $5.25 \%$ & $3.67 \%$ & $32.37 \%$ & $34.32 \%$ & $1.84 \%$ & $1.93 \%$ & $2.53 \%$ & $1.76 \%$ & $46.73 \%$ & $49.55 \%$ & $3.03 \%$ & $2.26 \%$ & $22.53 \%$ & $21.76 \%$ \\
\hline & $40-45$ & $5.63 \%$ & $6.10 \%$ & $6.39 \%$ & $4.17 \%$ & $35.61 \%$ & $37.76 \%$ & $1.22 \%$ & $1.58 \%$ & $4.19 \%$ & $2.26 \%$ & $51.40 \%$ & $54.50 \%$ & $4.69 \%$ & $2.76 \%$ & $24.19 \%$ & $22.26 \%$ \\
\hline & $45-49$ & $3.94 \%$ & $5.32 \%$ & $6.47 \%$ & $4.96 \%$ & $39.17 \%$ & $41.53 \%$ & $1.14 \%$ & $1.47 \%$ & $5.23 \%$ & $2.96 \%$ & $56.54 \%$ & $59.95 \%$ & $5.73 \%$ & $3.46 \%$ & $25.23 \%$ & $22.96 \%$ \\
\hline \multirow{7}{*}{ 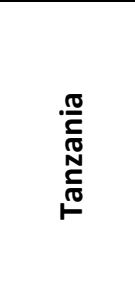 } & $15-19$ & $2.11 \%$ & $2.11 \%$ & $0.85 \%$ & $1.23 \%$ & $22.11 \%$ & $22.74 \%$ & $1.22 \%$ & $1.76 \%$ & $0.38 \%$ & $0.75 \%$ & $30.89 \%$ & $31.77 \%$ & $0.88 \%$ & $1.25 \%$ & $20.38 \%$ & $20.75 \%$ \\
\hline & $20-24$ & $4.16 \%$ & $6.06 \%$ & $1.53 \%$ & $2.18 \%$ & $24.33 \%$ & $25.02 \%$ & $1.95 \%$ & $2.68 \%$ & $0.51 \%$ & $0.66 \%$ & $33.98 \%$ & $34.95 \%$ & $1.01 \%$ & $1.16 \%$ & $20.51 \%$ & $20.66 \%$ \\
\hline & $25-29$ & $6.87 \%$ & $9.52 \%$ & $2.52 \%$ & $3.53 \%$ & $26.76 \%$ & $27.52 \%$ & $2.34 \%$ & $3.48 \%$ & $0.68 \%$ & $0.91 \%$ & $37.38 \%$ & $38.44 \%$ & $1.18 \%$ & $1.41 \%$ & $20.68 \%$ & $20.91 \%$ \\
\hline & $30-34$ & $8.57 \%$ & $12.88 \%$ & $4.28 \%$ & $4.38 \%$ & $29.43 \%$ & $30.27 \%$ & $2.46 \%$ & $2.95 \%$ & $1.79 \%$ & $0.48 \%$ & $41.12 \%$ & $42.29 \%$ & $2.29 \%$ & $0.98 \%$ & $21.79 \%$ & $20.48 \%$ \\
\hline & $35-39$ & $9.39 \%$ & $11.40 \%$ & $5.07 \%$ & $4.84 \%$ & $32.38 \%$ & $33.30 \%$ & $3.08 \%$ & $2.43 \%$ & $2.08 \%$ & $1.07 \%$ & $45.23 \%$ & $46.52 \%$ & $2.58 \%$ & $1.57 \%$ & $22.08 \%$ & $21.07 \%$ \\
\hline & $40-45$ & $12.33 \%$ & $9.88 \%$ & $6.39 \%$ & $5.49 \%$ & $35.62 \%$ & $36.63 \%$ & $1.60 \%$ & $1.34 \%$ & $2.08 \%$ & $1.93 \%$ & $49.76 \%$ & $51.17 \%$ & $2.58 \%$ & $2.43 \%$ & $22.08 \%$ & $21.93 \%$ \\
\hline & $45-49$ & $6.81 \%$ & $5.79 \%$ & $6.46 \%$ & $4.83 \%$ & $39.18 \%$ & $40.29 \%$ & $1.50 \%$ & $1.25 \%$ & $3.89 \%$ & $2.55 \%$ & $54.73 \%$ & $56.29 \%$ & $4.39 \%$ & $3.05 \%$ & $23.89 \%$ & $22.55 \%$ \\
\hline
\end{tabular}

* Four transition probabilities (out of 126 computed) were censored to zero. 


\section{Table 2: Selected Life Paths}

\begin{tabular}{|c|c|c|c|c|c|c|c|c|c|c|c|c|c|c|c|c|}
\hline \multirow{2}{*}{ Ind. $\mathbf{N}^{\circ}$} & \multirow{2}{*}{ Sex } & \multirow{2}{*}{$\begin{array}{l}\text { Age in } \\
2009\end{array}$} & \multirow{2}{*}{ Scenario } & \multicolumn{2}{|c|}{$2009 / 2013$} & \multicolumn{2}{|c|}{$2014 / 2018$} & \multicolumn{2}{|c|}{$2019 / 2023$} & \multicolumn{2}{|c|}{$2024 / 2028$} & \multicolumn{2}{|c|}{$2029 / 2033$} & \multicolumn{2}{|c|}{$2034 / 2038$} & \multirow{2}{*}{$\begin{array}{c}\text { 2009/2038 } \\
\text { Individual } \\
\text { GDP Gap }\end{array}$} \\
\hline & & & & $\mathbf{T}$ & $\mathbf{w}$ & $\mathbf{T}$ & w & $\mathbf{T}$ & w & $\mathbf{H}$ & $\mathbf{w}$ & H & $\mathbf{w}$ & $\mathbf{H}$ & $\mathbf{w}$ & \\
\hline \multirow{3}{*}{116} & \multirow{3}{*}{ Man } & \multirow{3}{*}{$20-24$} & No Access & 0 & $\$ 3,580$ & 0 & $\$ 4,015$ & ( & $\$ 4,080$ & 0 & $\$ 3,090$ & 0 & & 0 & & Reference \\
\hline & & & Universal Access w/ AE & \multirow{2}{*}{0} & $\$ 3,580$ & \multirow{2}{*}{0} & $\$ 4,015$ & \multirow{2}{*}{0} & $\$ 4,080$ & \multirow{2}{*}{0} & $\$ 3,710$ & 0 & $\$ 3,750$ & \multirow{2}{*}{$0 \&$} & \multirow{2}{*}{$\begin{array}{l}\$ 3,705 \\
\$ 4,120\end{array}$} & $\$ 8,075$ \\
\hline & & & Universal Access w/out AE & & $\$ 3,580$ & & $\$ 4,015$ & & $\$ 4,080$ & & $\$ 4,125$ & 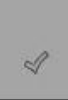 & $\$ 4,170$ & & & $\$ 9,325$ \\
\hline \multirow{3}{*}{3518} & \multirow{3}{*}{ Woman } & \multirow{3}{*}{$25-29$} & No Access & \multirow{3}{*}{$\begin{array}{l}0 \\
0\end{array}$} & $\$ 2,910$ & \multirow{3}{*}{0} & & \multirow{3}{*}{$\begin{array}{l}0 \\
0 \quad 1\end{array}$} & & \multirow{3}{*}{0} & & \multirow{3}{*}{ ? } & & & & Ref. \\
\hline & & & Universal Access w/ AE & & $\$ 3,495$ & & $\$ 3,570$ & & $\$ 3,625$ & & & & & & & $\$ 7,780$ \\
\hline & & & Universal Access w/out AE & & $\$ 3,885$ & & $\$ 3,970$ & & $\$ 4,030$ & & & & & & & $\$ 8,975$ \\
\hline & & & No Access & () & $\$ 3,970$ & 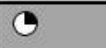 & $\$ 4,030$ & 9 & $\$ 3,070$ & 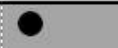 & & & & & & Ref. \\
\hline 6074 & Woman & 30-34 & Universal Access w/ AE & a & $\$ 3,970$ & C & $\$ 4,030$ & & $\$ 3,685$ & & & & & & & $\$ 615$ \\
\hline & & & Universal Access w/out AE & & $\$ 3,970$ & & $\$ 4,030$ & & $\$ 4,095$ & $\overrightarrow{0}$ & & & & & & $\$ 1,025$ \\
\hline & & & No Access & $\mathrm{O}$ & $\$ 4,125$ & 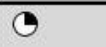 & $\$ 4,170$ & $x$ & $\$ 3,090$ & & & & & & & Ref. \\
\hline 6898 & Man & 35-39 & Universal Access w/ AE & $\Omega$ & $\$ 4,125$ & (- & $\$ 4,170$ & & $\$ 3,705$ & & & & & & & $\$ 615$ \\
\hline & & & Universal Access w/out AE & 0 & $\$ 4,125$ & & $\$ 4,170$ & & $\$ 4,120$ & & & & & & & $\$ 1,030$ \\
\hline & & & No Access & & & & & 9 & $\$ 1,790$ & 0 & & 0 & & O & & Ref. \\
\hline 16179 & Man & $\begin{array}{l}\text { New } \\
\text { Born }\end{array}$ & Universal Access w/ AE & & & & & & $\$ 2,150$ & & $\$ 3,220$ & & $\$ 3,615$ & & $\$ 3,670$ & $\$ 10,865$ \\
\hline & & & Universal Access w/out AE & & & & & & $\$ 2,390$ & 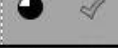 & $\$ 3,580$ & 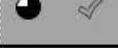 & $\$ 4,015$ & 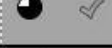 & $\$ 4,080$ & $\$ 12,275$ \\
\hline & & & No Access & & & & & & & $x$ & $\$ 1,490$ & 0 & & O & & Ref. \\
\hline 22494 & Woman & $\begin{array}{l}\text { New } \\
\text { Born }\end{array}$ & Universal Access w/ AE & & & & & & & & $\$ 1,790$ & 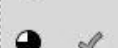 & $\$ 2,985$ & & & $\$ 3,285$ \\
\hline & & & Universal Access w/out AE & & & & & & & & $\$ 1,990$ & $q$ & $\$ 3,315$ & & & $\$ 3,815$ \\
\hline & iod GDP G & & Universal Access w/ AE & $\$ 585$ & [\$146] & $\$ 3,570$ & [\$-125] & $\$ 5,215$ & [\$442] & $\$ 4,140$ & [\$\$617] & $\$ 10,350$ & [\$3450] & $\$ 7,375$ & [\$3688] & $\$ 31,235$ \\
\hline & per capita] & & Universal Access w/out AE & $\$ 975$ & {$[\$ 244]$} & $\$ 3,970$ & {$[\$-25]$} & $\$ 6,685$ & [\$736] & $\$ 5,115$ & [\$942] & $\$ 11,500$ & [\$3833] & $\$ 8,200$ & [\$4100] & $\$ 36,445$ \\
\hline
\end{tabular}

\begin{tabular}{|c|c|c|c|}
\hline \multirow{3}{*}{ Legend : } & Health Status & ART Procurement & \\
\hline & $\begin{array}{ll}\bigcirc & \text { HIV - } \\
& \text { HIV + }\end{array}$ & $q$ Yes & Censored Future \\
\hline & $\begin{array}{l}\text { HIV + TN } \\
\text { Dead }\end{array}$ & $\times$ No & New Born \\
\hline
\end{tabular}

Some other trajectories: Individual 3518 required treatment in 2009. ART enables her to survive two additional periods and earn $\$ 7,780$ more $(\$ 8,975$ at full production capacity). Individual 6978 from the THIS is aged 35-39 in 2009. He is censored after three periods. ID 16179 is introduced in the $3^{\text {rd }}$ period already awaiting treatment. On condition that he receives ART, he survives and earns $\$ 12,655$ afterwards (against $\$ 1,790$ in $S 1$ and $\$ 14,065$ in $S 2$ at full productivity). 


\section{Table 3: Simulation Results}

\begin{tabular}{|c|c|c|c|c|c|c|}
\hline \multirow{2}{*}{ 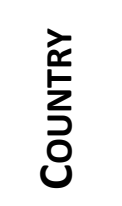 } & & \multirow[b]{2}{*}{ OUTCOMES } & \multirow[b]{2}{*}{$\begin{array}{l}\text { INITIAL } \\
\text { PERIOD }\end{array}$} & \multicolumn{3}{|c|}{ Final PERIOd } \\
\hline & & & & $\begin{array}{c}\text { No } \\
\text { Access }\end{array}$ & $\begin{array}{c}\text { Universal } \\
\text { Access } \\
\text { with } A E\end{array}$ & $\begin{array}{c}\text { Universal } \\
\text { Access } \\
\text { w/out AE }\end{array}$ \\
\hline \multirow{7}{*}{ 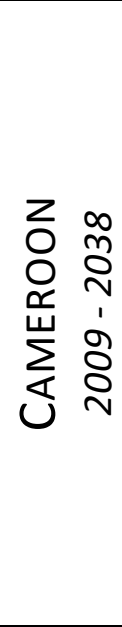 } & \multirow{3}{*}{ 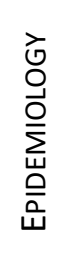 } & $\begin{array}{l}\text { Number of Adults aged 15-49 } \\
\text { (in thousands) }\end{array}$ & 9,154 & 18,482 & \multicolumn{2}{|c|}{18,738} \\
\hline & & HIV Prevalence (in \%) & 4.98 & 4.69 & \multicolumn{2}{|c|}{5.98} \\
\hline & & $\begin{array}{l}\text { ART requirement among } \\
\text { PLWHIV (in \%) }\end{array}$ & 29.8 & 27.1 & \multicolumn{2}{|c|}{43.7} \\
\hline & \multirow{4}{*}{ 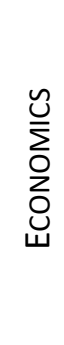 } & GDP per Capita (in USD) & 2,060 & 2,159 & 2,168 & 2,174 \\
\hline & & $\begin{array}{l}\text { GDP gap from } 2009 \text { onwards } \\
\text { (in USD billions) }\end{array}$ & $\mathrm{n} / \mathrm{a}$ & Ref & 13.71 & 16.36 \\
\hline & & $\begin{array}{l}\text { ART Costs from } 2009 \\
\text { onwards (in USD billions) }\end{array}$ & $\mathrm{n} / \mathrm{a}$ & 0 & \multicolumn{2}{|c|}{7.13} \\
\hline & & $\begin{array}{l}\text { GDP gap / ART Costs } \\
\text { (from } 2009 \text { onwards) }\end{array}$ & $\mathrm{n} / \mathrm{a}$ & Ref & 1.92 & 2.30 \\
\hline \multirow{7}{*}{ 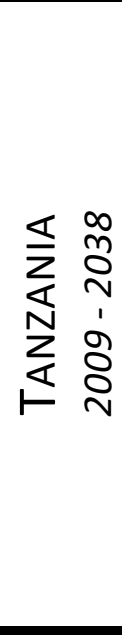 } & \multirow{3}{*}{ 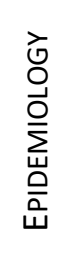 } & $\begin{array}{l}\text { Number of Adults aged 15-49 } \\
\text { (in thousands) }\end{array}$ & 18,783 & 36,894 & \multicolumn{2}{|c|}{37,418} \\
\hline & & HIV Prevalence (in \%) & 6.13 & 5.35 & \multicolumn{2}{|c|}{6.65} \\
\hline & & $\begin{array}{l}\text { ART requirement among } \\
\text { PLWHIV (in \%) }\end{array}$ & 31.7 & 25.6 & \multicolumn{2}{|c|}{41.7} \\
\hline & \multirow{4}{*}{ 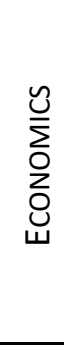 } & GDP per Capita (in USD) & 698 & 704 & 706 & 708 \\
\hline & & $\begin{array}{l}\text { GDP gap from } 2009 \text { onwards } \\
\text { (in USD billions) }\end{array}$ & $\mathrm{n} / \mathrm{a}$ & Ref & 9.13 & 11.06 \\
\hline & & $\begin{array}{l}\text { ART Costs from } 2009 \\
\text { onwards (in USD billions) }\end{array}$ & $\mathrm{n} / \mathrm{a}$ & 0 & \multicolumn{2}{|c|}{16.04} \\
\hline & & $\begin{array}{l}\text { GDP gap / ART Costs } \\
\text { (from } 2009 \text { onwards) }\end{array}$ & $\mathrm{n} / \mathrm{a}$ & Ref & 0.57 & 0.69 \\
\hline \multirow{7}{*}{ 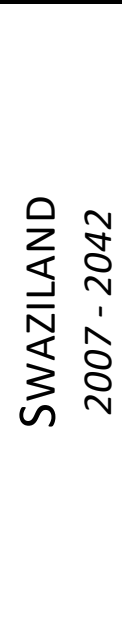 } & \multirow{3}{*}{ 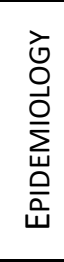 } & $\begin{array}{l}\text { Number of Adults aged 15-49 } \\
\text { (in thousands) }\end{array}$ & 582 & 1,600 & \multicolumn{2}{|c|}{1,707} \\
\hline & & HIV Prevalence (in \%) & 25.88 & 21.91 & \multicolumn{2}{|c|}{26.80} \\
\hline & & $\begin{array}{l}\text { ART need among PLWHIV } \\
\text { (in thousands) }\end{array}$ & 31.0 & 29.0 & \multicolumn{2}{|c|}{45.6} \\
\hline & \multirow{4}{*}{ 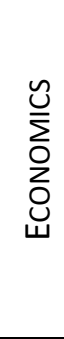 } & GDP per Capita (in USD) & 4,456 & 4,905 & 5,028 & 5,108 \\
\hline & & $\begin{array}{l}\text { GDP gap from } 2007 \text { onwards } \\
\text { (in USD billions) }\end{array}$ & $\mathrm{n} / \mathrm{a}$ & Ref & 14.66 & 17.48 \\
\hline & & $\begin{array}{l}\text { ART Costs from } 2007 \\
\text { onwards (in USD billions) }\end{array}$ & $\mathrm{n} / \mathrm{a}$ & 0 & \multicolumn{2}{|c|}{3.11} \\
\hline & & $\begin{array}{l}\text { GDP gap / ART Costs } \\
\text { (from } 2007 \text { onwards) }\end{array}$ & $\mathrm{n} / \mathrm{a}$ & Ref & 4.71 & 5.62 \\
\hline
\end{tabular}




\section{Figure 4: HIV Prevalence}
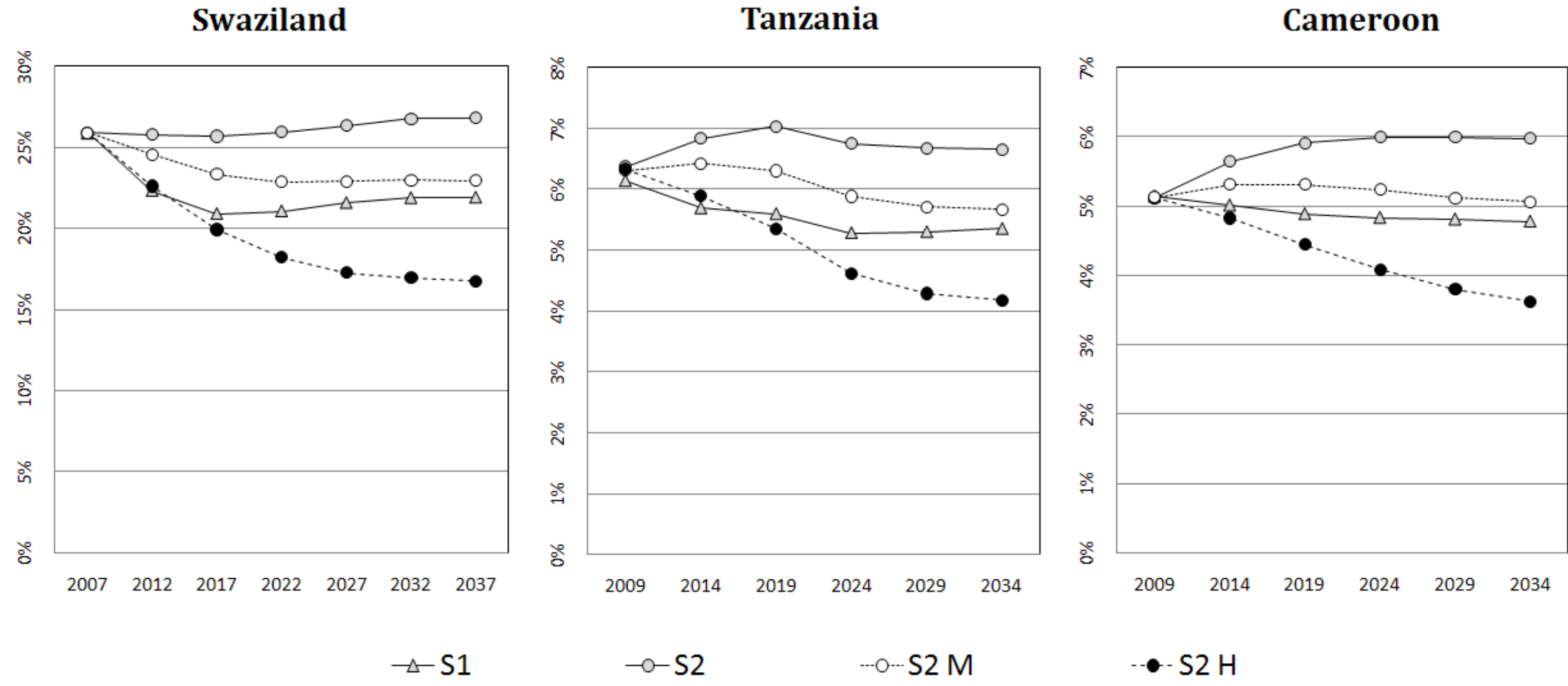


\section{Figure 5: Annual per capita GDP}
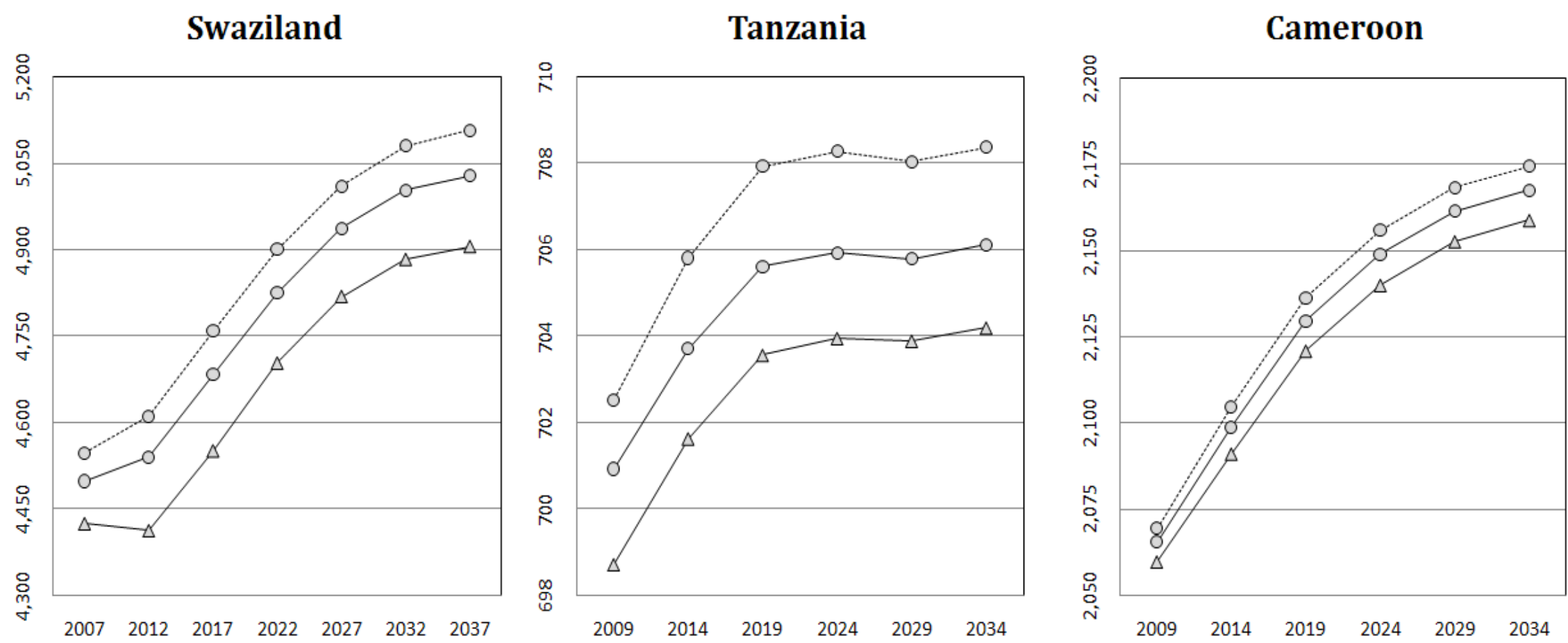

$\neg-$ No Access $\quad-0-$ S2 with Adverse Effect $\quad \cdots \circ-$ S2 without Adverse Effect 


\section{Figure 6: Decomposition of per capita GDP gains}

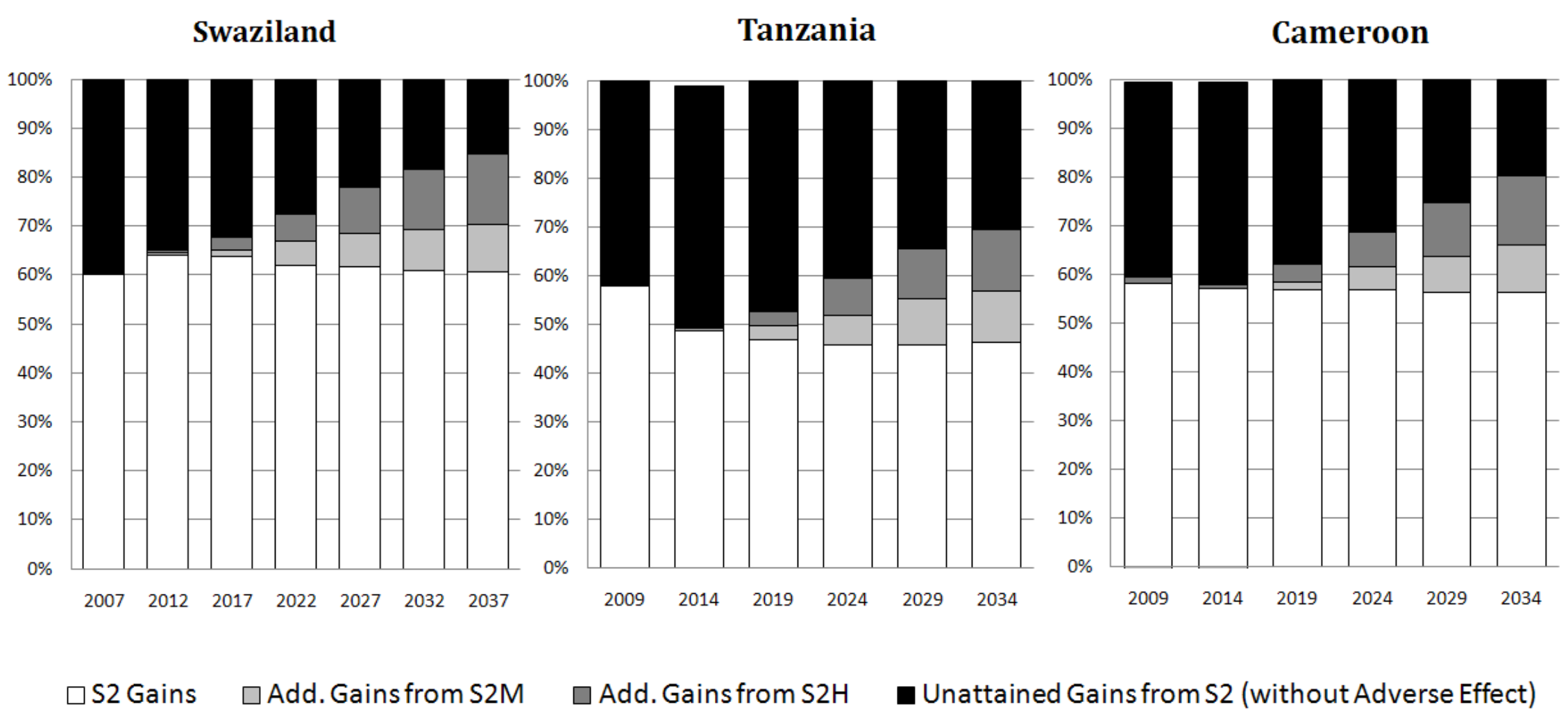




\section{Mathematical Appendix}

- Proof of inequality [6]. We obtain:

$$
\begin{gathered}
\frac{\partial y_{[2]}(\Delta)}{\partial \Delta}=\frac{m}{\left(m \cdot \lambda\left(h^{s}+\Delta\right)+(1-m) \cdot \lambda\left(h^{n s}\right)\right)^{2}}\left[\lambda\left(h^{s}+\Delta\right) \cdot f^{\prime}\left(h^{s}+\Delta\right)\left(m \cdot \lambda\left(h^{s}+\Delta\right)+(1-m) \cdot \lambda\left(h^{n s}\right)\right)-(1-m)\right. \\
\left.\cdot \lambda\left(h^{n s}\right) \lambda^{\prime}\left(h^{s}+\Delta\right)\left[f\left(h^{n s}\right)-f\left(h^{s}+\Delta\right)\right]\right]
\end{gathered}
$$

Thus, $\frac{\partial y_{[2]}(\Delta)}{\partial \Delta}$ has the sign of:

$$
\frac{f^{\prime}\left(h^{s}+\Delta\right) \lambda\left(h^{s}+\Delta\right)}{\lambda^{\prime}\left(h^{s}+\Delta\right) f\left(h^{s}+\Delta\right)}-\frac{(1-m) \cdot \lambda\left(h^{n s}\right)}{m \cdot \lambda\left(h^{s}+\Delta\right)+(1-m) \cdot \lambda\left(h^{n s}\right)} \times \frac{f\left(h^{n s}\right)-f\left(h^{s}+\Delta\right)}{f\left(h^{s}+\Delta\right)}
$$

- Proofs of Proposition 3 (Comparative statics)

We study how the threshold $\tilde{\Delta}$ varies with the different parameters of the model (assuming that inequality [6] is verified for all $\Delta \leq \Delta_{0}$ ). Let $F\left(h^{s}, h^{n s}, m, \tilde{\Delta}\right)$ be the implicit function of the form:

$$
F\left(h^{s}, h^{n s}, m, \tilde{\Delta}\right) \equiv y_{[2]}(\tilde{\Delta})-y_{[2]}(0)=0
$$

The partial derivative of $\tilde{\Delta}$ with respect to a given variable $z$ is $\frac{\partial \tilde{\Delta}}{\partial z}=-\frac{\partial F / \partial z}{\partial F / \partial \tilde{\Delta}}$

Since $\Delta_{0}<\tilde{\Delta}<\bar{\Delta}$, and since $y^{2}(\Delta)$ is increasing for all $\Delta \in\left[\Delta_{0}, \bar{\Delta}\right], \frac{\partial F}{\partial \tilde{\Delta}}=\frac{\partial y_{[2]}(\tilde{\Delta})}{\partial \tilde{\Delta}}>0 . \partial \tilde{\Delta} / \partial z$ and $\partial F / \partial z$ are thus of opposite signs.

- We first examine how $\tilde{\Delta}$ varies with respect to the prevalence of the disease $m$.

$$
\frac{\partial y_{[2]}(\Delta)}{\partial m}=\frac{\lambda\left(h^{n s}\right) \cdot \lambda\left(h^{s}+\Delta\right)\left(f\left(h^{s}+\Delta\right)-f\left(h^{n s}\right)\right)}{\left[m \cdot \lambda\left(h^{s}+\Delta\right)+(1-m) \cdot \lambda\left(h^{n s}\right)\right]^{2}}
$$


And thus :

$$
\frac{\partial F}{\partial m}=\frac{\partial\left(y_{[2]}(\tilde{\Delta})-y_{[2]}(0)\right)}{\partial m}=\lambda\left(h^{n s}\right)\left[\frac{\lambda\left(h^{s}\right)\left(f\left(h^{n s}\right)-f\left(h^{s}\right)\right)}{\left[m \cdot \lambda\left(h^{s}\right)+(1-m) \cdot \lambda\left(h^{n s}\right)\right]^{2}}-\frac{\lambda\left(h^{s}+\tilde{\Delta}\right)\left(f\left(h^{n s}\right)-f\left(h^{s}+\tilde{\Delta}\right)\right)}{\left[m \cdot \lambda\left(h^{s}+\tilde{\Delta}\right)+(1-m) \cdot \lambda\left(h^{n s}\right)\right]^{2}}\right]
$$

We show that the derivative of function $\frac{\lambda\left(h^{s}+\Delta\right)\left(f\left(h^{n s}\right)-f\left(h^{s}+\Delta\right)\right)}{\left[m \cdot \lambda\left(h^{S}+\Delta\right)+(1-m) \cdot \lambda\left(h^{n s}\right)\right]^{2}}$ with respect to $\Delta$ has the sign of:

$$
\lambda^{\prime}\left(h^{s}+\Delta\right)\left(f\left(h^{n s}\right)-f\left(h^{s}+\Delta\right)\right)\left((1-m) \cdot \lambda\left(h^{n s}\right)-m \lambda\left(h^{s}+\Delta\right)\right)-\lambda\left(h^{s}+\Delta\right) f^{\prime}\left(h^{s}+\Delta\right)\left[m \cdot \lambda\left(h^{s}+\Delta\right)+(1-m) \cdot \lambda\left(h^{n s}\right)\right]
$$

It is non-positive if and only if:

$$
\frac{f^{\prime}\left(h^{s}+\Delta\right)}{f\left(h^{s}+\Delta\right)} \frac{\lambda\left(h^{s}+\Delta\right)}{\lambda^{\prime}\left(h^{s}+\Delta\right)} \geq \frac{(1-m) \cdot \lambda\left(h^{n s}\right)-m \lambda\left(h^{s}+\Delta\right)}{m \cdot \lambda\left(h^{s}+\Delta\right)+(1-m) \cdot \lambda\left(h^{n s}\right)} \times \frac{f\left(h^{n s}\right)-f\left(h^{s}+\Delta\right)}{f\left(h^{s}+\Delta\right)}
$$

I.e. if: $e_{f / \lambda}(\Delta) \geq c(\Delta)-\frac{m \lambda\left(h^{s}+\Delta\right)}{m \cdot \lambda\left(h^{s}+\Delta\right)+(1-m) \cdot \lambda\left(h^{n s}\right)} \times \frac{f\left(h^{n s}\right)-f\left(h^{s}+\Delta\right)}{f\left(h^{s}+\Delta\right)}$

According to inequality [6], this is true for all $\Delta \geq \Delta_{0}$ and for some $\Delta \in\left[0, \Delta_{0}[\right.$

Therefore, we have:

$$
\frac{\lambda\left(h^{s}\right)\left(f\left(h^{n s}\right)-f\left(h^{s}\right)\right)}{\left[m \cdot \lambda\left(h^{s}\right)+(1-m) \cdot \lambda\left(h^{n s}\right)\right]^{2}} \geq \frac{\lambda\left(h^{s}+\tilde{\Delta}\right)\left(f\left(h^{n s}\right)-f\left(h^{s}+\tilde{\Delta}\right)\right)}{\left[m \cdot \lambda\left(h^{s}+\tilde{\Delta}\right)+(1-m) \cdot \lambda\left(h^{n s}\right)\right]^{2}}
$$

And $\tilde{\Delta}$ is a decreasing function of $m$.

- We examine how $\tilde{\Delta}$ varies with respect to the initial health status of the ill population

We know that $y_{[2]}(\cdot)$ is decreasing in $\Delta$ for all $\Delta \leq \Delta_{0}$ and increases in $\Delta$ for all $\Delta \geq \Delta_{0}$.

Since it is perfectly equivalent to derive $y_{[2]}(\cdot)$ with respect to $\Delta$ or to $h^{s}, \frac{\partial y_{[2]}(\tilde{\Delta})}{\partial h^{s}} \geq 0 ; \frac{\partial y_{[2]}(\Delta=0)}{\partial h^{s}} \leq 0$

Therefore, $\frac{\partial F}{\partial h^{s}}=\frac{\partial y^{2}(\tilde{\Delta})}{\partial h^{s}}-\frac{\partial y^{2}(0)}{\partial h^{s}} \geq 0: \tilde{\Delta}$ is a decreasing function of $h^{s}$. 
- We then examine how $\tilde{\Delta}$ varies with respect to the initial health status of the healthy population:

$$
\begin{gathered}
\frac{\partial F}{\partial h^{n s}}=\frac{\partial y^{2}(\tilde{\Delta})}{\partial h^{n s}}-\frac{\partial y^{2}(\Delta=0)}{\partial h^{n s}} \\
\frac{\partial y^{2}(\Delta)}{\partial h^{n s}}=(1-m) \frac{\lambda\left(h^{n s}\right) f^{\prime}\left(h^{n s}\right)\left(m \lambda\left(h^{s}+\Delta\right)+(1-m) \lambda\left(h^{n s}\right)\right)+m \lambda^{\prime}\left(h^{n s}\right) \lambda\left(h^{s}+\Delta\right)\left(f\left(h^{n s}\right)-f\left(h^{s}+\Delta\right)\right)}{\left[m \cdot \lambda\left(h^{s}+\Delta\right)+(1-m) \cdot \lambda\left(h^{n s}\right)\right]^{2}}
\end{gathered}
$$

After simplifications, we obtain:

$$
\begin{aligned}
\frac{\partial^{2} y^{2}(\Delta)}{\partial h^{n s} \partial \Delta}=\frac{m(1-m)}{[m} & \left.\quad \lambda\left(h^{s}+\Delta\right)+(1-m) \cdot \lambda\left(h^{n s}\right)\right]^{3} \\
& \times\left[\lambda^{\prime}\left(h^{n s}\right) \lambda^{\prime}\left(h^{s}+\Delta\right)\left(f\left(h^{n s}\right)-f\left(h^{s}+\Delta\right)\right)\left((1-m) \cdot \lambda\left(h^{n s}\right)-m \lambda\left(h^{s}+\Delta\right)\right)\right. \\
& \left.\quad-\left(m \cdot \lambda\left(h^{s}+\Delta\right)+(1-m) \cdot \lambda\left(h^{n s}\right)\right)\left(\lambda\left(h^{s}+\Delta\right) \lambda^{\prime}\left(h^{n s}\right) f^{\prime}\left(h^{s}+\Delta\right)+\lambda^{\prime}\left(h^{s}+\Delta\right) \lambda\left(h^{n s}\right) f^{\prime}\left(h^{n s}\right)\right)\right]
\end{aligned}
$$

Rearranging the above expression, $\frac{\partial F}{\partial h^{n s}}=\frac{\partial y^{2}(\tilde{\Delta})}{\partial h^{n s}}-\frac{\partial y^{2}(\Delta=0)}{\partial h^{n s}}$ is non-positive, and $\tilde{\Delta}$ is a non-decreasing function of $h^{n s}$ if and only if:

$$
\begin{gathered}
\frac{f^{\prime}\left(h^{s}+\Delta\right) / f\left(h^{s}+\Delta\right)}{\lambda^{\prime}\left(h^{s}+\Delta\right) / \lambda\left(h^{s}+\Delta\right)}+\frac{f^{\prime}\left(h^{n s}\right)}{\lambda^{\prime}\left(h^{n s}\right) / \lambda\left(h^{n s}\right)} \geq \frac{(1-m) \cdot \lambda\left(h^{n s}\right)-m \lambda\left(h^{s}+\Delta\right)}{m \cdot \lambda\left(h^{s}+\Delta\right)+(1-m) \cdot \lambda\left(h^{n s}\right)} \times \frac{f\left(h^{n s}\right)-f\left(h^{s}+\Delta\right)}{f\left(h^{s}+\Delta\right)} \\
\Leftrightarrow e_{f / \lambda}(\Delta)+f\left(h^{n s}\right) e_{f / \lambda}(\bar{\Delta}) \geq c(\Delta)-\frac{m \cdot \lambda\left(h^{s}+\Delta\right)}{m \cdot \lambda\left(h^{s}+\Delta\right)+(1-m) \cdot \lambda\left(h^{n s}\right)} \times \frac{f\left(h^{n s}\right)-f\left(h^{s}+\Delta\right)}{f\left(h^{s}+\Delta\right)}
\end{gathered}
$$

This condition is always satisfied.

- Finally, we examine how $\tilde{\Delta}$ varies with respect to the degree of concavity of the production function relative to the survival function.

We develop here a particular case, for concave power production functions $f(h)=h^{\alpha}$, with $0<\alpha<1$, and for an identity survival function: $\lambda(h)=h$. We can rewrite equation [5] as:

$$
y_{[2]}(\Delta)=\frac{m \cdot\left(h^{s}+\Delta\right)^{1+\alpha}+(1-m) \cdot\left(h^{n s}\right)^{1+\alpha}}{m \cdot\left(h^{s}+\Delta\right)+(1-m) \cdot h^{n s}}
$$




$$
\begin{gathered}
\frac{\partial y^{2}(\Delta)}{\partial \alpha}=\frac{m \cdot \ln \left(h^{s}+\Delta\right)\left(h^{s}+\Delta\right)^{1+\alpha}+(1-m) \cdot \ln \left(h^{n s}\right)\left(h^{n s}\right)^{1+\alpha}}{m \cdot\left(h^{s}+\Delta\right)+(1-m) \cdot h^{n s}} \\
\frac{\partial^{2} y^{2}(\Delta)}{\partial \alpha \partial \Delta}=\frac{m\left(h^{s}+\Delta\right)^{\alpha}}{\left(m \cdot\left(h^{s}+\Delta\right)+(1-m) \cdot h^{n s}\right)^{2}}\left[m \cdot\left(h^{s}+\Delta\right)\left(1-\alpha \ln \left(\frac{1}{h^{s}+\Delta}\right)\right)+(1-m)\right. \\
\left.\cdot h^{n s}\left(1-(1+\alpha) \ln \left(\frac{1}{h^{s}+\Delta}\right)+\ln \left(\frac{1}{h^{n s}}\right)\left(\frac{h^{n s}}{h^{s}+\Delta}\right)^{\alpha}\right)\right]
\end{gathered}
$$

Based on numerical simulations, we find that this quantity is negative when the health impact of the epidemic is sufficiently large (which is also one of the conditions to verify equation [6]. Details can be provided upon request.

Thus, if $\frac{\partial y^{2}(\Delta)}{\partial \alpha \partial \Delta} \leq 0, \frac{\partial F}{\partial \alpha}=\frac{\partial y^{2}(\tilde{\Delta})}{\partial \alpha}-\frac{\partial y^{2}(\Delta=0)}{\partial \alpha} \leq 0$ and $\frac{\partial \tilde{\Delta}}{\partial \alpha} \geq 0$ : the threshold $\tilde{\Delta}$ decreases when $f(\cdot)$ is more concave. 


\section{Main parameters from the microsimulation model}

\begin{tabular}{|c|c|c|c|c|c|}
\hline \multirow{3}{*}{ Demographic } & \multirow{2}{*}{ 15-24 Population } & \multirow[b]{2}{*}{ Growth Rate } & \multirow{2}{*}{$\begin{array}{c}\text { Swaziland } \\
14.18 \% \\
\end{array}$} & \multirow{2}{*}{$\begin{array}{c}\text { Tanzania } \\
13.56 \% \\
\end{array}$} & \multirow{2}{*}{$\begin{array}{c}\text { Cameroon } \\
11.71 \% \\
\end{array}$} \\
\hline & & & & & \\
\hline & Sample size & & 8,187 & 10,747 & 9,751 \\
\hline \multirow[t]{16}{*}{ Economics } & \multirow{10}{*}{$\begin{array}{l}\text { Logit (Employment): } \\
\text { Coefficients }\end{array}$} & $15 \leq$ Age $<20$ & & $* * *$ Ref*** & \\
\hline & & $20 \leq$ Age $<25$ & 1.538 & 1.339 & 1.299 \\
\hline & & $25 \leq$ Age $<30$ & 2.378 & 2.284 & 2.025 \\
\hline & & $30 \leq$ Age $<35$ & 2.649 & 2.514 & 2.618 \\
\hline & & $35 \leq$ Age $<40$ & 2.836 & 2.702 & 2.929 \\
\hline & & $40 \leq$ Age $<45$ & 2.696 & 2.934 & 3.094 \\
\hline & & $45 \leq$ Age $<50$ & 2.691 & 2.677 & 2.977 \\
\hline & & Male & & $* * * \operatorname{Ref} * * *$ & \\
\hline & & Female & -0.7567 & -0.369 & -0.596 \\
\hline & & Intercept & -1.58 & 0.196 & -0.663 \\
\hline & \multirow{4}{*}{ Productivity Rates } & HIV - & & $100 \%$ & \\
\hline & & HIV+ & & $100 \%$ & \\
\hline & & $H I V++$ under $A R T$ & & $90 \%$ & \\
\hline & & HIV++ untreated & & $75 \%$ & \\
\hline & GDP at market prices & Per Capita, in billions & $\$ 2.648$ & $\$ 11.351$ & $\$ 15.775$ \\
\hline & Avg. Annual Wage & Per Worker & $\$ 10,381$ & $\$ 870$ & $\$ 3,223$ \\
\hline
\end{tabular}

